\title{
Managing Credit Bubbles
}

\author{
Alberto Martin and Jaume Ventura*
}

March 2015

\begin{abstract}
We study a dynamic economy where credit is limited by insufficient collateral and, as a result, investment and output are too low. In this environment, changes in investor sentiment or market expectations can give rise to credit bubbles, that is, expansions in credit that are backed not by expectations of future profits (i.e. fundamental collateral), but instead by expectations of future credit (i.e. bubbly collateral). Credit bubbles raise the availability of credit for entrepreneurs: this is the crowding-in effect. But entrepreneurs must also use some of this credit to cancel past credit: this is the crowding-out effect. There is an "optimal" bubble size that trades off these two effects and maximizes long-run output and consumption.

The equilibrium bubble size depends on investor sentiment, however, and it typically does not coincide with the "optimal" bubble size. This provides a new rationale for macroprudential policy. A credit man-

\footnotetext{
*Martin: CREI , Universitat Pompeu Fabra and Barcelona GSE, amartin@ crei.cat. Ventura: CREI, Universitat Pompeu Fabra and Barcelona GSE, jventura@ crei.cat. CREI, Universitat Pompeu Fabra, Ramon Trias Fargas 25-27, 08005-Barcelona, Spain. A previous version of this paper was circulated under the title "Bubbly Collateral and Economic Activity". We thank Zeno Enders, Emilio Espino, Raquel Fernandez, Bernardo Guimaraes, Zhiguo He, Joachim Jungherr, Fabrizio Perri, and Oren Sussmann for very helpful discussions. We acknowledge support from the Spanish Ministry of Science and Innovation (ECO2011-23197), the Generalitat de Catalunya (grants 2009SGR1157, DIUE and 2014SGR830 AGAUR), and the Barcelona GSE Research Network. In addition, both Martin and Ventura acknowledge support from the ERC (Consolidator Grant FP7-615651 and Advanced Grant
} FP7-249588-ABEP, respectively), and Martin thanks the IMF Research Fellowship.
\end{abstract}


agement agency (CMA) can replicate the "optimal" bubble by taxing credit when the equilibrium bubble is too high and subsidizing credit when the equilibrium bubble is too low. This leaning-against-the-wind policy maximizes output and consumption. Moreover, the same conditions that make this policy desirable guarantee that a CMA has the resources to implement it.

JEL classification: E32, E44, O40

Keywords: bubbles, credit, business cycles, economic growth, financial frictions, pyramid schemes 
Credit markets play an increasingly central role in modern economies. Within the OECD, for instance, domestic credit has risen from 100\% of GDP in 1970 to approximately 160\% of GDP in 2012 (Figure 1). This growth masks large variations across countries and over time (Figure 2). And yet, there is a common feature to all these different country experiences that stands out: credit has often alternated periods of rapid growth or "booms", with periods of stagnation or significant decline or "busts". Moreover, there is some evidence that these credit booms and busts have become more common in recent years. ${ }^{1}$

Consider the case of the United States, where credit has grown more or less continuously throughout the sample period. Even there, it grew by approximately 40 percent of GDP between 1990 and 2010, only to contract sharply afterwards. In Greece, Ireland, Spain and Portugal, the dynamics of credit look similar during the last decades: stagnant or declining credit between the mid 1980s and the mid 1990s, a spectacular surge in credit between the mid-1990s and 2010, and stagnation or a sharp decline since then. Looking ahead, these drops in credit need not be short-lived as the Japanese and Swedish experiences show. In Japan, for instance, credit grew rapidly in the late 1990s and has fallen steadily since its 1999 peak. In Sweden, credit collapsed during the financial crisis of the early 1990s and it took over a decade to return to its previous peak.

These credit booms and busts tend to be accompanied by changes in key economic variables. It has been well documented that credit booms are associated with high asset prices and high growth rates of real GDP,

\footnotetext{
${ }^{1}$ See Mendoza and Terrones (2012) and Dell'Ariccia et al. (2012) for a brief discussion on the formal definition and empirical identification of credit booms. Mendoza and Terrones (2012) analyze the evolution of private credit to the private sector in 61 countries between 1960 and 2010 and identify 70 credit booms: each of the countries plotted in Figure 2 contains at least one of these. Dell'Ariccia et al. (2012) analyze data on bank credit to the domestic private sector in 170 countries between 1960 and 2010. They identify 175 credit booms, which translates into a $14 \%$ probability of a country experiencing a credit boom in any given year. They also document that credit booms appear to have become more common over time, in the sense that the fraction of countries experiencing a credit boom in any given year has been increasing since the 1980s. Claessens et al. (2011) use a different approach and study "credit cycles", but they also find them to be common: in a sample of 21 advanced economies between 1960 and 2007 , they are able to identify 114 such cycles.
} 
consumption and investment. According to some estimates the growth rate of investment doubles during booms. ${ }^{2}$ In spite of this, credit booms are still viewed with concern by policymakers and academics. The reason is that they eventually end, and their aftermaths are often characterized by financial crises and low economic growth. ${ }^{3}$ This has prompted calls for policies that restrain credit during booms, in the hope that smaller booms will lead to smaller crises.

To evaluate the merit of these calls for policy, one must have a view of the forces driving these credit cycles. Credit may fluctuate for variety of reasons, and different types of fluctuations may call for different policy responses. At a very general level, fluctuations in credit may reflect changes in demand or in supply. And these, in turn, may reflect changes in a variety of factors like preferences, technology or expectations. In this paper, we follow the large body of recent macroeconomic research on the "financial accelerator" and focus on credit fluctuations that are driven by fluctuations in borrowing constraints. The narrative is simple. When a borrower obtains credit, she is exchanging goods today for a promise to deliver goods in the future. These promises are only valued by savers if they have some guarantee of being repaid. One can think of this guarantee as the future income of entrepreneurs that can be credibly pledged to savers. We refer to this pledgeable income as the economy's stock of collateral. If entrepreneurs are constrained, it is this stock of collateral that determines the amount of promises that can be issued. If entrepreneurs are constrained, understanding boom-bust episodes like those shown above requires a theory of collateral fluctuations. This paper provides such a theory.

Our key innovation is to distinguish between fundamental and bubbly collateral. Fundamental collateral is the part of a borrower's pledgeable income that corresponds to future output, i.e. it consists of a bor-

\footnotetext{
${ }^{2}$ See Mendoza and Terrones (2012) and Dell' Ariccia et al. (2012).

${ }^{3}$ Dell' Ariccia et al. (2012) find that one third of credit booms end up in financial crises. Mendoza and Terrones (2012) find slightly lower numbers. The recent financial crisis in the United States also provides evidence in this regard: it was those regions that experienced the largest credit booms in the run up to the crisis that suffered the greater increase in credit delinquency during the crisis (Dell'Ariccia et al. 2008, Mian and Sufi 2009).
} 
rower's rights to future production. Bubbly collateral is instead the part of a borrower's pledgeable income that corresponds to future credit, i.e. it consists of a borrower's rights to future borrowing. We call this type of collateral bubbly because it constitutes a bubble or pyramid scheme in which present contributions (present credit) purchase future contributions (future credit): as long as the return to these bubbles or pyramid schemes is no lower than the interest rate, lenders will be willing to accept them as collateral. The macroeconomic literature has exclusively focused on fundamental collateral, studying its implications for credit, investment and growth. This view of collateral is incomplete, though. Whenever fundamental collateral is insufficient (say, because of weak enforcement institutions), we show that there is room for investor optimism to sustain bubbles that expand the economy's stock of collateral and total credit. The intuition behind this result is that the lack of fundamental collateral reduces the demand for credit and thus the equilibrium interest rate, thereby lowering the rate at which bubbles must grow in order for them to be attractive to savers. In this manner, the lack of fundamental collateral relaxes the conditions for bubbly collateral to exist.

What are the macroeconomic effects of bubbly collateral? By definition, it enables entrepreneurs to obtain credit in excess of their fundamental collateral: intuitively, current entrepreneurs can obtain "excess" credit today because it is expected that there will be "excess" credit in the future as well. This is the crowding-in effect of bubbles, which ceteris paribus increases investment. But this future "excess" credit will divert some of the resources of future generations away from investment. This is the crowding-out effect of bubbles, which ceteris paribus reduces investment. The macroeconomic consequences of bubbles depend on the relative strength of these two effects. In particular, we find that the crowding-in effect dominates when bubbly collateral is low, and the crowding-out effect dominates when bubbly collateral is high. This gives rise to an "optimal" bubble which trades-off these two effects and provides the amount of bubbly collateral that maximizes long-run output and consumption.

An essential feature of bubbly collateral is that its stock is driven by investor sentiment or market ex- 
pectations. The credit obtained by entrepreneurs today depends on market expectations about the credit that entrepreneurs will obtain tomorrow, which in turn depend on tomorrow's market expectations about the credit that entrepreneurs will obtain on the day after, and so on. Because of this, markets may sometimes provide too much bubbly collateral and sometimes too little of it, which creates a natural role for stabilization policies. We show that a credit management agency with the authority to tax and subsidize credit can in fact replicate the optimal bubble allocation. To do so, it must adopt a policy of leaning-against-the-wind, taxing credit when bubbly collateral is excessive and subsidizing it when bubbly collateral is scarce. We explore the implications of this policy and show that it raises output and consumption, although it may sometimes increase macroeconomic volatility. We argue that, to some extent, this policy can be interpreted as a scheme in which the credit management agency purchases assets to manage the economy's stock of collateral. Finally, we show that the same conditions that make bubbly collateral possible guarantee that a credit management agency always has enough resources to implement the desired policy.

The paper is organized as follows. Section 1 develops our basic model of collateral, credit and investment. Section 2 explores bubbly equilibria and studies the implications of bubbly collateral for dynamics and welfare. Section 3 introduces a credit management agency and shows how credit-market interventions can be used to maximize output and consumption. Section 4 explores the issue of a fiscal backstop, i.e. of the resources required to sustain the desired policy. Section 5 concludes. Before moving on, we offer a short review of related literature.

\section{Literature review:}

The model developed here builds upon previous work by Martin and Ventura (2011, 2012). In Martin and Ventura (2012), we analyzed the existence and macroeconomic effects of bubbles in an economy with extreme financial frictions that impede credit. In Martin and Ventura (2011), we extended the analysis to an economy with credit, and argued that bubbles could be a source of collateral. Those papers used a simple growth economy to establish two key results regarding financial frictions and bubbles. First, financial 
frictions that limit borrowers' ability to pledge their future income, and thus the economy's stock of fundamental collateral, relax the conditions for the existence of bubbles: the reason, as we mentioned above, is that such frictions lower the equilibrium interest rate and thus the rate at which bubbles must grow in order for them to be attractive to savers. Second, financial frictions make it possible for bubbles to be expansionary: the reason is that, by raising the economy's stock of collateral, bubbles may in theory raise credit and investment. Relative to those papers, we now: (i) fully characterize the effects of bubbly collateral, identifying the conditions under which it is expansionary or contractionary, and; (ii) analyze the effects of macroprudential policies, and of the resources required to implement them.

Our paper is obviously related to a large body of research that deals with fluctuations in credit, both empirically and theoretically. The former has sought to identify empirical regularities of credit booms and busts: Gourinchas et al. (2001), Claessens et al. (2011), Mendoza and Terrones (2012), Dell'Ariccia et al. (2012) and Schularick and Taylor (2012) fall within this category. On the theoretical front, various papers have tried to model "credit cycles" as an equilibrium outcome of competition in financial markets. Some examples of this work are Ruckes (2004), Dell'Ariccia and Marquez (2006), Matsuyama (2007), Gorton and He (2008) and Martin (2008). Like us, these papers model fluctuations in credit. Unlike us, though, these papers emphasize the role of institutional features of financial markets - like regulation or the incentives of certain market participants - in generating and magnifying fluctuations in credit. We take instead a macroeconomic perspective and argue that, when fundamental collateral is scarce, investor sentiment may give rise to credit bubbles.

From a methodological perspective, thus, this paper is closest to the literature that has studied the effects of bubbles in the presence of financial frictions: (i) unlike us, Caballero and Krishnamurthy (2006), Farhi and Tirole (2011) and Miao and Wang (2011) focus on the role of bubbles as a useful source of liquidity; (ii) like us, Kocherlakota (2009) focuses on the role of bubbles as collateral or net worth; and (iii) unlike us, Ventura (2011) focuses on the effects of bubbles on the cost of capital. There is also a long tradition of 
papers that view fiat money as a bubble, like Samuelson (1958) and Kiyotaki and Moore (2008). Our model is also related to the vast work on macroeconomic models with financial frictions, going back to Bernanke and Gertler (1989) and Kiyotaki and Moore (1997), in which collateral plays a key role in determining the level of financial intermediation and economic activity. Our contribution relative to this work is that we distinguish between fundamental and bubbly collateral.

Our study of policy is related to the literature on bailouts. Bailouts are commonly rationalized as a way to stimulate economic activity in the event of a crisis, by transferring resources towards distressed agents. In a macroeconomic model with financial frictions, for instance, Gertler and Kiyotaki (2012) show how policies that provide credit to distressed agents can reduce the severity of a crisis. At the same time, the prevailing view is that bailouts generate costs ex ante by distorting incentives (e.g. Farhi and Tirole 2012). The credit subsidies that we study are not really bailouts because they are financed through taxes on entrepreneurs themselves, i.e., they entail no net transfers to entrepreneurs as a whole. They are akin to bailouts, though, because they are given to entrepreneurs to repay their debts. The effects of these subsidies are different from those emphasized in the literature, however. They have positive effects on economic activity ex ante because, as in Ranciere et al. (2008), the expectation of future bailouts raises collateral; but they are costly to execute ex post because they divert resources away from investment.

Finally, this paper is related to the recent work that stresses the role of information insensitive collateral such as Dang et al. (2011) and Gorton and Ordoñez (2012). This research emphasizes the role of the financial system in generating collateral that is accepted by everyone without fear of adverse selection, because it does not pay for any agent to produce private information regarding its underlying characteristics. Of course, these incentives may change during a crisis, in which case information is generated and the value of collateral might experience large swings. In our model, it is also natural to think of bubbly collateral as information insensitive relative to fundamental collateral. The value of bubbly collateral depends on investor sentiment or market expectations which are public information. The value of fundamental collateral depends 
instead on the regular business activity of the underlying firm or financial institution, which is likely to be influenced by managers through a variety of channels that are difficult to observe and give rise to private information.

\section{The bubbly economy}

The starting point of our analysis is the classic Diamond (1965) model of capital accumulation with overlapping generations. The young supply labor, consume part of their labor income and save the rest. These savings are used to purchase capital from the old and to produce new capital. The old own the capital, demand labor and consume their capital income.

Tirole (1985) extended the Diamond model by introducing an additional market for bubbles or pyramid schemes. Participants in a pyramid scheme make voluntary contributions that entitle them to receive the next contribution. Thus, we say that an individual purchases a bubble when he/she makes a contribution to a pyramid scheme. Similarly, we say that an individual sells a bubble when he/she receives a contribution from the pyramid scheme. Starting a bubble or pyramid scheme yields a windfall to the first participant, which consists of the first contribution to the scheme. We assume that each generation starts new bubbles with random initial value. These new bubbles are traded in the market for bubbles alongside the old bubbles started by previous generations. ${ }^{4}$

The model we present here adds a credit market to the Tirole model, as sketched in the last section of Martin and Ventura (2012). In the Diamond and Tirole models there is only intergenerational trade. Here we create gains from intragenerational trade by introducing heterogeneity within generations. While some individuals have savings (the 'savers'), other individuals have investment opportunities (the 'entrepreneurs'). By investment opportunities, we mean both capital and bubbles. Young savers give credit to young entrepreneurs and, in return, old entrepreneurs pay a (possibly contingent) interest rate to old savers.

\footnotetext{
${ }^{4}$ The arrival of new bubbles is an important departure from the original Tirole model that plays a key role in our theory.
} 
Our emphasis is precisely on the workings of this credit market. If this market worked well, the equilibria of our model would not differ from those of the Tirole model. The credit market would simply allow savers to effectively own capital and bubbles, since competition among entrepreneurs would ensure that equilibrium credit contracts replicate the payoffs of owning capital and bubbles. But imperfect enforcement institutions limit the collateral of entrepreneurs and impair the workings of the credit market. ${ }^{5}$ By collateral, we mean the old-age resources that young entrepreneurs can pledge to young savers. In this section, we describe our model and show how the set of equilibria depends on the availability of collateral.

\subsection{The basic setup}

Consider an economy inhabited by a sequence of equal-sized and overlapping generations of young and old. Time starts in period $t=0$ and then goes on forever. The objective of individual $i$ of generation $t$ is to maximize his/her utility $U_{t}^{i}$, given by:

$$
U_{t}^{i}=C_{t, t}^{i}+\beta \cdot E_{t} C_{t, t+1}^{i}
$$

where $\beta>0$; and $C_{t, t}^{i}$ and $C_{t, t+1}^{i}$ are the young-age and old-age consumptions of individual $i$ generation t. Naturally, consumption must be non-negative, i.e. $C_{t, t}^{i} \geq 0$ and $C_{t, t+1}^{i} \geq 0$. As usual, $E_{t}\{\cdot\}$ denotes the mathematical expectation of the corresponding variable.

Each generation contains two types of individuals. Savers work during youth, save part of their labor income and lend it to finance old-age consumption. Entrepreneurs borrow during youth to finance purchases of capital and bubbles, and produce during old age.

Savers supply one unit of labor during youth and decide how much of their labor income to save. They use their savings to purchase credit contracts in exchange for a gross, possibly contingent, interest rate of

\footnotetext{
${ }^{5}$ Imperfect enforcement institutions do not impair the workings of the markets for labor, capital or bubbles since transactions in these markets do not involve a promise by the seller to deliver future payments to the buyer. Thus, labor, capital and bubbles can be traded even in situations in which credit is not possible or severely restricted.
} 
$R_{t+1}$ units of output in period $t+1$ for each unit of output used to purchase credit contracts in period $t$. We refer to $R_{t+1}$ as the contingent or ex post interest rate, and we refer to $E_{t} R_{t+1}$ as the interest rate. In old age, savers receive the return to their savings and consume. Thus, their consumptions are given by:

$$
\begin{gathered}
C_{t, t}^{i}=W_{t}-L_{t}, \\
C_{t, t+1}^{i}=R_{t+1} \cdot L_{t},
\end{gathered}
$$

where $W_{t}$ is the wage and $L_{t}$ is savings or the value of credit contracts purchased. Equation (2) says that young-age consumption equals labor income minus savings, while Equation (3) says that old-age consumption equals the return to savings. Savers maximize utility in Equation (1) subject to the budget constraints in Equation (2) and (3).

Entrepreneurs invest and produce. Their production technology can be described by the following CobbDouglas function:

$$
F\left(K_{t}, N_{t}\right)=A_{t} \cdot K_{t}^{\alpha} \cdot\left(\gamma^{t} \cdot N_{t}\right)^{1-\alpha}
$$

where $K_{t}$ is capital, $\alpha \in(0,1)$ and $\gamma>1$. Labor productivity grows at the constant rate $\gamma \geq 1$. We refer to $A_{t}$ as a productivity shock and assume that it fluctuates randomly over time. The production of one unit of capital requires one unit of the consumption good. We assume that capital fully depreciates in production.

Entrepreneurs also initiate and trade bubbles. We use $B_{t}$ to denote the value of the bubbles in period $t$. Some of these bubbles are old since they were initiated by previous generations of entrepreneurs and were purchased by entrepreneurs of generation $t-1$. Some of these bubbles are new since they are initiated by entrepreneurs of generation $t-1$. Thus, the aggregate bubble evolves as follows:

$$
B_{t+1}=R_{t+1}^{B} \cdot B_{t}+B_{t+1}^{N}
$$

where $R_{t+1}^{B}$ is the increase in price or return to the bubbles purchased from entrepreneurs of generation $t-1$; and $B_{t+1}^{N}$ the value of the bubbles initiated by the entrepreneurs of generation $t$. We refer to $B_{t+1}^{N}$ as bubble creation and we assume that it is non-negative, i.e. $B_{t+1}^{N} \geq 0$. 
To finance their activities, entrepreneurs sell credit contracts to savers. These contracts can be fully state contingent but must be collateralized, that is, they must be backed by credible promises of future payments. This brings us to the key friction that underlies all the analysis of this paper: imperfect enforcement institutions limit the amount of available collateral. In particular, entrepreneurs can hide a fraction $1-\phi$ of their capital income from enforcement institutions, so that:

$$
R_{t+1} \cdot L_{t} \leq \phi \cdot\left[F\left(K_{t+1}, N_{t+1}\right)-W_{t+1} \cdot N_{t+1}\right]+B_{t+1} .
$$

Equation (6) states that promised payments cannot exceed a fraction $\phi \in[0,1]$ of their capital income plus their bubbles. We think of the first term as the "fundamental" collateral of entrepreneurs, and of the second term as their "bubbly" collateral. ${ }^{6}$ Throughout the paper, we refer to Equation (6) as the credit or collateral constraint. As $\phi \rightarrow 1$, the entire capital income can be used as collateral for credit and the credit constraint coincides with the restriction that old-age consumption be non-negative, i.e. $C_{t, t+1}^{i} \geq 0$. This limiting case is the frictionless economy.

With these assumptions, we can write the consumptions of entrepreneurs as follows:

$$
\begin{aligned}
C_{t, t}^{i} & =L_{t}-K_{t+1}-B_{t}, \\
C_{t, t+1}^{i} & =F\left(K_{t+1}, N_{t+1}\right)-W_{t+1} \cdot N_{t+1}+B_{t+1}-R_{t+1} \cdot L_{t} .
\end{aligned}
$$

Equation (7) says that young-age consumption equals credit minus investment and the purchases bubbles, while Equation (8) says that old-age consumption equals production net of labor costs plus the value of bubbles minus credit payments. Entrepreneurs maximize utility in Equation (1) subject to the budget constraints in Equations (7), (8), the credit constraint in Equation (6) and the law of motion for bubbles in Equation (5).

\footnotetext{
${ }^{6}$ One way to think about this constraint is that courts can grab all the consumption goods that are traded in the market but only a fraction $\phi$ of those that are not traded.
} 


\subsection{Markets and prices}

We are ready to solve the model. In the labor market, old entrepreneurs demand labor until the marginal product equals the wage. Since young savers supply one unit of labor, $N_{t}=1$, this means that:

$$
w_{t}=(1-\alpha) \cdot A_{t} \cdot k_{t}^{\alpha}
$$

As usual, we use lowercase letters to refer to variables in units of efficient workers so that, for instance, $k_{t} \equiv \gamma^{-t} \cdot K_{t}$. Equation (9) says that labor income is a constant fraction $1-\alpha$ of production.

In the market for bubbles, old entrepreneurs sell bubbles to young ones. Old entrepreneurs supply all their bubbles provided the price is nonnegative. Young entrepreneurs, as we have seen, finance the purchase of bubbles by selling credit contracts. If the expected return to holding bubbles falls short of the interest rate, young entrepreneurs make a loss when they sell credit contracts to finance bubble purchases and the demand for bubbles is zero. If the expected return to holding bubbles exceeds the interest rate, young entrepreneurs make a profit when they borrow to purchase bubbles and the demand for bubbles is unbounded. Thus, equilibrium requires that the expected return to holding bubbles equals the interest rate:

$$
E_{t} R_{t+1}^{B}=E_{t} R_{t+1}
$$

This does not mean, of course, that the realized return to holding bubbles equals the realized return to credit contracts.

Finally, we move to the credit market where young savers supply credit to young entrepreneurs. Note first that $\alpha \cdot E_{t} A_{t+1} \cdot k_{t+1}^{\alpha-1} \geq E_{t} R_{t+1} \geq \beta^{-1}$ in equilibrium. ${ }^{7}$ Using this observation, the supply of credit by

\footnotetext{
${ }^{7}$ This can be shown by contradiction. Assume first that $E_{t} R_{t+1}>\alpha \cdot E_{t} A_{t+1} \cdot k_{t+1}^{\alpha-1}$. Then, entrepreneurs would not want to sell credit contracts and $\alpha \cdot E_{t} A_{t+1} \cdot k_{t+1}^{\alpha-1}=\infty>\beta^{-1}$; while savers would like to spend all their income purchasing credit contracts. Thus, it follows that $\alpha \cdot E_{t} A_{t+1} \cdot k_{t+1}^{\alpha-1} \geq E_{t} R_{t+1}$. Assume next that $\beta^{-1}>E_{t} R_{t+1}$. Then, savers would not want to purchase credit contracts and $\alpha \cdot E_{t} A_{t+1} \cdot k_{t+1}^{\alpha-1}=\infty>\beta^{-1}$; while entrepreneurs would want to sell as many credit contracts as allowed by their constraint. Thus, it follows that $E_{t} R_{t+1} \geq \beta^{-1}$.
} 
young savers can be described as follows:

$$
l_{t}\left\{\begin{array}{ll}
=w_{t} & \text { if } \quad \beta \cdot E_{t} R_{t+1}>1 \\
\in\left[0, w_{t}\right] & \text { if } \quad \beta \cdot E_{t} R_{t+1}=1
\end{array} .\right.
$$

If the interest rate exceeds the discount rate, young savers save all their income. If the interest rate equals the discount rate, young savers are indifferent between saving and consuming.

The demand for credit by young entrepreneurs can be written as follows:

$$
E_{t} R_{t+1}=\left\{\begin{array}{lll}
\alpha \cdot E_{t} A_{t+1} \cdot k_{t+1}^{\alpha-1} & \text { if } & E_{t} b_{t+1}^{N} \geq(1-\phi) \cdot \alpha \cdot E_{t} A_{t+1} \cdot k_{t+1}^{\alpha} \\
\frac{\phi \cdot \alpha \cdot E_{t} A_{t+1} \cdot k_{t+1}^{\alpha}+E_{t} b_{t+1}}{\gamma^{-1} \cdot l_{t}} & \text { if } & E_{t} b_{t+1}^{N}<(1-\phi) \cdot \alpha \cdot E_{t} A_{t+1} \cdot k_{t+1}^{\alpha}
\end{array} .\right.
$$

Equation (12) depicts the maximum interest rate that entrepreneurs are willing and able to pay per unit of credit, respectively. Whether the credit constraint is binding or not depends on whether expected bubble creation exceeds the capital income that is not pledgeable. If it does, then the credit constraint is not binding because entrepreneurs have enough collateral to pledge the entire return to investment: in this case, the interest rate is equal to the expected marginal return to investment. If it does not, then the credit constraint is binding because entrepreneurial collateral is insufficient to pledge the entire return to investment: in this case, the maximum interest rate that entrepreneurs are able to pay is determined by the ratio of expected collateral (fundamental and bubbly) to credit. $^{8}$

\footnotetext{
${ }^{8}$ There is an interesting wrinkle that arises when the credit constraint is binding and $E_{t} b_{t+1}^{N}=0$. In that case, the only possible equilibrium entails $E_{t} R_{t+1}=\phi \cdot \alpha \cdot E_{t} A_{t+1} \cdot k_{t+1}^{\alpha-1}$ : at that interest rate, though, individual entrepreneurs (who take the return to investment as given) are unconstrained and they demand infinite credit. Competition cannot bid up the interest rate, moreover, because entrepreneurs are already pledging the maximum share of their income that is feasible given enforcement constraints. In such a situation, clearing of the credit market requires rationing. We assume that this rationing works as follows: given $\alpha$. $E_{t} A_{t+1} \cdot k_{t+1}^{\alpha-1}$ entrepreneurs offer to borrow an amount $L_{t}$ at an interest rate $E_{t} R_{t+1}$; in the event that the interest rate offered by all entrepreneurs is the same, the total supply of credit is allocated equally across entrepreneurs. There are two possibilities: (i) $E_{t} R_{t+1}>\beta^{-1}$, in which case savers strictly prefer to lend their resources to entrepreneurs and the supply of credit equals the economy's wage bill; (ii) $E_{t} R_{t+1}=\beta^{-1}$, in which case savers are indifferent between lending in the credit market or consuming
} 
To complete the solution, we need to determine how entrepreneurs use the credit they receive, and this is as follows:

$$
\gamma \cdot k_{t+1}+b_{t}\left\{\begin{array}{lll}
=l_{t} & \text { if } & \beta \cdot \alpha \cdot E_{t} A_{t+1} \cdot k_{t+1}^{\alpha-1}>1 \\
\in\left[0, l_{t}\right] & \text { if } & \beta \cdot \alpha \cdot E_{t} A_{t+1} \cdot k_{t+1}^{\alpha-1}=1
\end{array} .\right.
$$

Equation (13) says that entrepreneurs consume in the first period only if the marginal product of capital equals $\beta^{-1}$. Otherwise, entrepreneurs use all the credit they receive to invest and purchase bubbles.

\subsection{Equilibrium dynamics}

To obtain some intuitions about the workings of the model, it is useful to collapse the previous equations as follows:

$$
\begin{gathered}
k_{t+1}\left\{\begin{array}{c}
=\frac{1-\alpha}{\gamma} \cdot A_{t} \cdot k_{t}^{\alpha}-\frac{b_{t}}{\gamma} \quad \text { if } \quad \beta \cdot E_{t} R_{t+1}>1 \\
\in\left[0, \frac{1-\alpha}{\gamma} \cdot A_{t} \cdot k_{t}^{\alpha}-\frac{b_{t}}{\gamma}\right] \quad \text { if } \quad \beta \cdot E_{t} R_{t+1}=1
\end{array}\right. \\
E_{t} R_{t+1}=\min \left\{\alpha \cdot E_{t} A_{t+1}, E_{t}\left\{\left(\phi \cdot \alpha+n_{t+1}\right) \cdot A_{t+1}\right\}\right\} \cdot k_{t+1}^{\alpha-1}, \\
b_{t+1}=\frac{E_{t} R_{t+1}+u_{t+1}}{\gamma} \cdot b_{t}+n_{t+1} \cdot A_{t+1} \cdot k_{t+1}^{\alpha},
\end{gathered}
$$

where $u_{t+1}$ is the unexpected component of bubble returns and $n_{t+1}$ is the value of new bubbles as a share of output, i.e. $u_{t+1} \equiv R_{t+1}^{B}-E_{t} R_{t+1}^{B}$ and $n_{t+1} \equiv b_{t+1}^{N} /\left(A_{t+1} \cdot k_{t+1}^{\alpha}\right)$. We refer to $u_{t}$ and $n_{t}$ as bubble-return and bubble-creation shocks, respectively. Equations (14) and (15) describe the supply and demand of funds for investment, respectively. Equation (16) describes the dynamics of the bubble. Jointly, Equations (14)-(16) provide a full description of the dynamics of the state variables, i.e. $k_{t}$ and $b_{t}$; for any admissible sequence of productivity and bubble shocks, i.e. $A_{t}, u_{t}$ and $n_{t}$. Thus, we refer to them as the law of motion of the system.

Figure 3 shows how the interest rate and next period's capital stock are determined by solving Equations (14) and (15). If the capital stock is low, the interest rate is above the discount rate and young savers use during youth and equilibrium lending is exactly equal to $\left(\beta \cdot \phi \cdot \alpha \cdot E_{t} A_{t+1}\right)^{\frac{1}{1-\alpha}}$. This issue does not arise when $E_{t} b_{t+1}>0$, however small, and it therefore plays a minor role in our analysis. 
all their income to purchase credit contracts. In this case, collateral is abundant and the capital stock is determined by the supply of funds. We label this range of capital stocks the region of full intermediation. If the capital stock is high, the interest rate equals the discount rate and young savers consume part of their income. In this case, collateral is scarce and the capital stock is determined by the demand for funds. We label this range of capital stocks the region of partial intermediation.

Figure 4 shows how productivity and bubbles affect the supply and demand of funds for investment and, thus, the law of motion. High realized productivity raises the supply of funds, while high expected productivity raises collateral and the demand for funds. Bubble return shocks are embedded in the size of the bubble. The higher is the size of the bubble the lower is the supply of funds. High realized bubble creation raises the size of the bubble and lowers the supply of funds, but high expected bubble creation raises collateral and the demand for funds. These intuitions are crucial to understand the results that follow.

To construct equilibria for this economy, we propose first a joint stochastic process for bubble return and creation shocks: $\left\{u_{t}, n_{t}\right\}$ for all $t$. Naturally, this bubble process must be such that $E_{t} u_{t+1}=0$ and $n_{t} \geq 0$ for all $t$. We adopt the convention that $b_{-1}=0$ and set $n_{0}$ to ensure that $b_{0}$ takes the desired starting value. With this stochastic process at hand, we determine all possible sequences for the state variables $\left\{k_{t}, b_{t}\right\}$ using Equations (14)-(16). If all these sequences are such that $k_{t} \geq 0$ and $b_{t} \geq 0$, we say that the proposed bubble process is an equilibrium. Otherwise, we say that the proposed bubble process is not an equilibrium.

The bubbleless equilibrium is that one in which the bubble process takes this form: $\left\{u_{t}, n_{t}\right\}=\{0,0\}$ for all $t$. The bubbleless equilibrium always exists and it is a useful reference. But there are additional bubbly equilibria and these we find more interesting.

\subsection{Discussion}

Before moving on, we write a few words about the nature of bubbles for those readers that remain skeptical about this modeling strategy. Convinced readers can skip this section. A bubble is nothing but a pyramid 
scheme. Participants in a pyramid scheme make a voluntary contribution to the scheme that gives them right to the next voluntary contribution. Even though this might seem quite abstract or exotic at first sight, it is easy to find real-world situations that correspond fairly well to this concept. Consider, for instance, credit given to a firm in excess of the net present value of the cash-flows that this firm will generate. This credit is often labeled "excessive". But this "excessive" credit is rational if creditors expect the firm to obtain "excessive" credit also in the future. Thus, "excessive" credit can be interpreted as a voluntary contribution to the firm that gives the right to the next voluntary contribution. This leads us to think of real-world firms as portfolios of capital and bubbles. And this is exactly what the entrepreneurs in our model stand for. Naturally, the savers in our model stand for those that rationally provide credit to real-world firms.

Let us try to pursue this view a bit further and see how we could re-interpret our model in terms of firms and the stock market. Production and investment must take place within firms that are owned and managed by entrepreneurs. Young entrepreneurs purchase pre-existing firms in the stock market or create new ones at zero cost. Let $V_{t}$ denote the value of all firms, i.e. the value of the stock market. To finance their activities, entrepreneurs sell credit contracts $L_{t}=I_{t}+V_{t}$, where $I_{t}$ is investment and the capital stock evolves as follows:

$$
K_{t+1}=I_{t}+(1-\delta) \cdot K_{t}
$$

where $\delta$ is the depreciation rate, which we have assumed to be one for simplicity. Entrepreneurs can only pledge to their creditors a fraction $\phi$ of profits and the re-sale value of their firms. As a result, the following credit constraint applies:

$$
R_{t+1} \cdot L_{t} \leq \phi \cdot\left[F\left(K_{t+1}, N_{t+1}\right)-W_{t+1} \cdot N_{t+1}\right]+V_{t+1}
$$

Under this re-interpretation, the model shows that there are many equilibria in which firm prices take this form:

$$
V_{t}=(1-\delta) \cdot K_{t}+B_{t},
$$


where $(1-\delta) \cdot K_{t}$ and $B_{t}$ are the fundamental and bubble components of firm prices. ${ }^{9}$ In this re-interpretation of the theory, there is no market for bubbles, instead there is a stock market in which portfolios of capital and bubbles are traded. Note that, in the case of full depreciation that we focus on, we can directly re-interpret the market for bubbles as the stock market. Thus, it is stock market bubbles (or more generally, bubbles in firm values even if these are not traded in organized stock exchanges) that feed credit booms and busts!

An interesting issue that arises in this re-interpretation of the model refers to the nature of bubble creation. Diba and Grossman (1988) argued that, if a bubble exists on a stock or firm price, then it started on the first date of trading of the firm. To reach this conclusion, they noted that bubble creation at any date after the first date of trading would involve an innovation in the firm price. But this innovation must have had a zero expected value if it was not priced in the first date of trading. Up to here, their argument indicates that expected bubble creation after the first date of trading of a firm must be zero. Diba and Grossman did not stop here and noted also that in some popular setups free disposal of firms rules out negative bubbles. In these setups, there is an even stronger restriction on bubble creation. If new bubbles must be nonnegative and their expected value must be zero after the first date of trading, then bubble creation can only take place in the first date of trading.

Since we study throughout equilibria in which expected bubble creation is positive, it might be useful to see how we go around the Diba-Grossman argument. As them, we assume free-disposal and rule out negative bubbles as they do, $B_{t}^{N} \geq 0$. But once we know that in our model the market for bubbles is nothing but the market for firms, $V_{t}=B_{t}$, it is straightforward to re-interpret Equation (5) (which we reproduce here for convenience) in terms of firm prices:

$$
B_{t}=R_{t}^{B} \cdot B_{t}+B_{t}^{N},
$$

\footnotetext{
${ }^{9}$ This assumes that the price of capital is one. This is the case if old and new units of capital are indistinguishable and investment is always strictly positive. If different capital vintages were distinguishable, for instance, there could also be a bubble component in the price of capital(s). We ignore this complication here.
} 
$B_{t}$ is the price of all the firms in the economy and it includes old or pre-existing firms, $R_{t}^{B} \cdot B_{t}$; and newly created firms, $B_{t}^{N}$. The argument that bubble creation must be zero after the first date of trading implies $E_{t} R_{t+1}^{B}=E_{t} R_{t+1}$. And indeed, this is what Equation (10) says. But the Diba-Grossman argument does not impose any restriction on the size of the bubble in the first trading date of firms. This is why $E_{t} B_{t+1}^{N}>0$ is possible. Positive expected bubble creation after the first date of trading is also possible once some of the restrictive assumptions used by Diba and Grossman are relaxed. But proving this would take us too far afield and it is not needed here.

\section{Bubbly equilibria}

Entrepreneurs wish to purchase bubbles if these grow at least as fast as the interest rate. Entrepreneurs can raise enough funds to purchase bubbles if these do not grow faster than the economy. Thus, bubbly equilibria are possible if and only if the interest rate does not exceed the growth rate.

It is well known that this situation arises if the frictionless economy is dynamically inefficient. In this case, the interest rate is low because the supply of funds is high and the economy overinvests. Bubbles reduce unproductive investment and this allows the economy to sustain a higher level of consumption and welfare. We do not want to focus on this case however. ${ }^{10}$

It is somewhat less known that, even if the frictionless economy is dynamically efficient, the interest rate might fall below the growth rate if financial frictions limit the stock of fundamental collateral. In this case, the interest rate is low because the demand for funds is low and, if anything, there might be underinvestment. This is indeed the case we focus on here.

Throughout, we assume that $\beta \cdot \gamma>1$. This condition ensures that individuals are patient enough to save

\footnotetext{
${ }^{10}$ One reason is that dynamic inefficiency is believed to be rare in practice (see Abel et al. 1988), although this has been recently challenged by Geerolf (2012). Another reason is that, in this case bubbly equilibria are always associated with declines in investment and output, which seems counterfactual.
} 
even if the interest rate is below the growth rate. Without this condition, the interest rate would never fall short of the growth rate and bubbly equilibria would not be possible in our model.

\subsection{Bubbly business cycles}

It seems natural to start with the case in which there are no productivity shocks, i.e. $A_{t}=A$. We also adopt the following assumption:

$$
\frac{1}{2}<\alpha<\frac{1}{1+\phi}
$$

The first inequality ensures that the frictionless economy is dynamically efficient and investment is always productive. Thus, bubbly equilibria exist only if the demand for funds is depressed. The second inequality ensures that this is indeed the case. That is, collateral is scarce and this lowers the demand for funds enough to make bubbly equilibria possible.

The existence of bubbly equilibria of this sort does not imply that there is underinvestment in the bubbleless equilibrium. If

$$
\frac{1}{1+\beta \cdot \gamma \cdot \phi}<\alpha<\frac{1}{1+\phi}
$$

the steady state of the bubbleless equilibrium lies in the region of full intermediation. The interest rate is low enough to make bubbly equilibria possible, but not low enough to lead to underinvestment. If

$$
\frac{1}{2}<\alpha<\frac{1}{1+\beta \cdot \gamma \cdot \phi}
$$

the steady state of the bubbleless equilibrium lies in the region of partial intermediation. In this case, the interest rate is low enough not only to make bubbly equilibria possible, but also to lead to underinvestment.

Let us consider first a 'quiet' bubble process: $\left\{u_{t}, n_{t}\right\}=\{0, n\}$ for all $t$. This deterministic bubble is an equilibrium if $n$ is low enough. From any initial condition, the economy converges to the following steady state:

$$
k^{*}=\min \left\{\frac{1-\alpha}{\gamma} \cdot A \cdot\left(k^{*}\right)^{\alpha}-\frac{b^{*}}{\gamma},[\beta \cdot(\phi \cdot \alpha+n) \cdot A]^{\frac{1}{1-\alpha}}\right\}
$$




$$
b^{*}=\frac{\gamma \cdot n \cdot A \cdot\left(k^{*}\right)^{\alpha}}{\gamma-(\phi \cdot \alpha+n) \cdot A \cdot\left(k^{*}\right)^{\alpha-1}} .
$$

Equation (18) and (19) jointly determine the steady state values for the capital stock and bubble. One can think of $n$ as an index of the size of the bubble. A higher value of $n$ leads to a higher steady state bubble, for at least two reasons. The first and direct one is that a higher value of $n$ raises the value of new bubbles that are created in each period. The second and more indirect reason is that a higher value of $n$ raises the interest rate, thereby raising the rate at which the value of old bubbles grows.

Figure 5 shows the effects of $n$ on the steady state values of capital, the bubble, credit, the interest rate and utility. By utility we mean the sum of utilities of savers and entrepreneurs, i.e. $U_{t}=\sum_{i} U_{t}^{i}{ }^{11}$ The Figure shows the case in which the steady state of the bubbleless equilibrium is located in the region of partial intermediation and there is underinvestment. The effects of the size of the bubble on the capital stock and utility have an inverse U-shape. Small bubbles raise credit and investment. This crowding-in effect of bubbles raises the capital stock and welfare. But if the bubbles are too large, the economy enters the region of full intermediation and the effects of bubbles change. Large bubbles raise the interest rate and displace productive investment. The crowding-out effect returns. The larger the bubble the larger is this crowding out effect. Indeed, if the bubble is large enough, utility is lower than if there is underinvestment.

There is therefore an 'optimal' bubble that provides the amount of collateral that maximizes the capital stock and utility in the steady state. This bubble is the one that places the economy at the frontier of the partial and full intermediation regions, eliminating underinvestment without raising the interest rate. A smaller bubble would provide too little collateral and the funds available for investment would be too low. A larger bubble would raise the interest rate and the funds available for investment would also be too low.

The 'quiet' bubble provides the basic intuition for what is to come later. But, if fluctuations in credit are driven by bubbles in the real world, these bubbles are everything but quiet. Thus, we consider next

\footnotetext{
${ }^{11}$ For now, the reader should focus only on the solid lines in Figures 5, 6, and 7. The dashed lines, which depict the behavior of these same variables under policy interventions, will be analyzed in section 3 .
} 
an economy that experiences 'bubbly episodes'. In particular, we assume that the economy starts in the fundamental state where $b_{t}=n_{t}=0$. The economy can transition to one of many bubbly states which we index by $j=1, \ldots, J$. Let $\varepsilon_{j}$ be the probability of reaching bubbly state $j$ from the fundamental state. When the economy abandons a bubbly state, it returns to the fundamental state. Let $\delta_{j}$ be the probability that the economy reaches the fundamental state from bubbly state $j$. We refer to the interval that goes from the first period the economy reaches bubbly state $j$ to the first period in which it returns to the fundamental state as a 'bubbly episode of type $j$ '. Let $z_{t}$ be the state of the economy, i.e. $z_{t} \in\left\{F, B_{1}, \ldots, B_{J}\right\}$. During a bubbly episode of type $j$, we have that

$$
n_{t}=n_{j} \quad \text { and } \quad u_{t+1}=\left\{\begin{array}{ll}
{\left[\phi \cdot \alpha+\left(1-\delta_{j}\right) \cdot n_{j}\right] \cdot A \cdot k_{t+1}^{\alpha-1} \cdot \frac{\delta_{j}}{1-\delta_{j}}} & \text { if } \quad z_{t+1}=B_{j} \\
-\left[\phi \cdot \alpha+\left(1-\delta_{j}\right) \cdot n_{j}\right] \cdot A \cdot k_{t+1}^{\alpha-1} & \text { if } \quad z_{t+1}=F
\end{array} .\right.
$$

The assumption that bubble creation is constant is just for convenience. The assumption about bubble returns says that, during a bubbly episode, the expected return to holding the bubble equals that of credit contracts. Conditional on the bubbly episode not ending, the return on the bubble will exceed that of credit contracts. But this is only compensation for the risk of the bubbly episode ending and the bubble bursting. ${ }^{12}$

With these assumptions, the dynamics of the economy can be written as follows:

$$
\begin{gathered}
k_{t+1}\left\{\begin{array}{ll}
\min \left\{\frac{1-\alpha}{\gamma} \cdot A \cdot k_{t}^{\alpha},[\beta \cdot(\phi \cdot \alpha+\varepsilon \cdot n) \cdot A]^{\frac{1}{1-\alpha}}\right\} & \text { if } z_{t}=F \\
\min \left\{\frac{1-\alpha}{\gamma} \cdot A \cdot k_{t}^{\alpha}-\frac{b_{t}}{\gamma},\left[\beta \cdot\left(\phi \cdot \alpha+\left(1-\delta_{j}\right) \cdot n_{j}\right) \cdot A\right]^{\frac{1}{1-\alpha}}\right\} & \text { if } z_{t}=B_{j}
\end{array},\right. \\
b_{t}= \begin{cases}0 & \text { if } \quad z_{t}=F \\
\frac{\left(\phi \cdot \alpha+\left(1-\delta_{j}\right) \cdot n_{j}\right) \cdot A \cdot k_{t}^{\alpha-1}}{\gamma \cdot\left(1-\delta_{j}\right)} \cdot b_{t-1}+n_{j} \cdot A \cdot k_{t}^{\alpha} & \text { if } \quad z_{t}=B_{j}\end{cases}
\end{gathered}
$$

where $\varepsilon \cdot n=\sum_{j} \varepsilon_{j} \cdot n_{j}$. Equation (21) describes the behavior of the capital stock. Its evolution in each period depends on whether investment is determined by the supply or demand for funds. It is worth mentioning that

\footnotetext{
${ }^{12}$ Naturally, the economy with the 'quiet' bubble analyzed in Figure 3 is the limiting case of the economy with 'bubbly episodes' in which there is a bubbly state with $\varepsilon_{j} \rightarrow 1, \delta_{j} \rightarrow 0$ and $n_{j}=n$. The economy enters this state at the beginning of time with probability one and never leaves it.
} 
the probability of a bubbly episode starting raises the demand for funds in the fundamental state. Thus, the behavior of the economy in the fundamental state is not equivalent to that of the bubbleless equilibrium. ${ }^{13}$ Equation (22) describes the evolution of the bubble during an episode of type $j$. Note that the growth of the bubble depends on how large and risky it is, i.e. $n_{j}$ and $\delta_{j}$. The larger and riskier, the faster it grows.

We show next some simulations. To produce them, we choose parameter values that ensure that the steady state of the bubbleless equilibrium is located in the region of partial intermediation. Then, we create four bubbly states that differ in terms of the size of the bubble and its risk:

\begin{tabular}{|c|c|c|}
\hline Size $\backslash$ Risk & safe & risky \\
\hline small & $\left(n_{S}, \delta_{S}\right)$ & $\left(n_{S}, \delta_{R}\right)$ \\
\hline large & $\left(n_{L}, \delta_{S}\right)$ & $\left(n_{L}, \delta_{R}\right)$ \\
\hline
\end{tabular}

where $n_{S}<n_{L}$ and $\delta_{S}<\delta_{R}$. We also assume that all these bubbles are equally likely, i.e. $\varepsilon_{j}=\varepsilon$. Finally, we generate a sequence of 10,000 values for $z_{t}$, and start the economy in the steady state so that we record 10,000 periods of steady state behavior.

Figure 6 plots the simulated time series of $k_{t}, E_{t} R_{t+1}, l_{t}, U_{t}$ and $b_{t}$ during a window of 200 periods. The Figure also shows the mean and standard deviation of these variables computed with the entire series of 10,000 periods. Given the length of the simulation, these sample statistics are excellent approximations to their corresponding theoretical counterparts. The figure illustrates that, depending on their characteristics, some bubbles crowd-in capital while others crowd-out capital. Take the first bubble in the sample: in this case, the bubble is small and safe and it raises the economy's capital stock. The interest rate remains constant at $\beta^{-1}$ throughout the episode, which confirms that there is not enough bubbly collateral to fully intermediate

\footnotetext{
${ }^{13}$ We have assumed that the probability and type of bubbly episodes are constant over time and therefore expected bubble creation is constant when the economy is in the fundamental state, i.e. $\varepsilon \cdot n$. This assumption is not necessary. We could have assumed instead that there are fluctuations in expected bubble creation in the fundamental state. In this case, even in the fundamental state the economy would be subject to changes in investor sentiment.
} 
wages. Contrast these effects with those of the next two bubbles, which are large. Initially, both bubbles raise the economy's capital stock: after a while, though, they both become too large and reduce capital accumulation. The interest rises above $\beta^{-1}$ during both episodes, confirming that there is too much bubbly collateral. The figure also illustrates that riskier bubbles grow faster because they must compensate potential buyers for their risk of bursting. To see this, compare the two episodes around periods 8030 and 8040 . Both bubbles are of the same size but the first one is riskier: thus, even though the first episode lasts less than the second one, the maximum size of the bubble is larger. One implication of this is that, conditional on not bursting, riskier bubbles become larger and have more severe crowding-out effects.

These examples illustrate two key aspects of credit bubbles. The first one is that they have mixed effects on the economy. Bubble creation provides collateral to the current generation and this allows it to raise credit and expand investment. But bubble creation also requires future generations to cancel this additional credit and this diverts some of their resources away from investment. In this regard, we can think of the crowding-out effect of bubbles as an "overhang" effect, in the sense that growth is hurt by bubbles that were created in the past. The second point is that credit bubbles can follow very different paths, potentially much more complicated than the ones explored here, and they may have very different effects on output and welfare. This naturally suggests a role for policy in selecting or replicating a desirable equilibrium. Before going there, though, we need to deal with another layer of complexity: real-world economies are not only subject to bubble shocks but also to fundamental ones.

\subsection{Bubbly and real business cycles}

Let us bring back productivity shocks. In particular, assume that $A_{t}$ can take two positive values: $A_{t} \in$ $\left\{A_{L}, A_{H}\right\}$ with $A_{L} \leq A_{H}$. The transition probability is $\eta \leq 0.5$, i.e. $\operatorname{Prob}\left(A_{t+1} \neq A_{t}\right)=\eta$. We define $E A_{L} \equiv E_{t}\left\{A_{t+1} / A_{t}=A_{L}\right\}$ and $E A_{H} \equiv E_{t}\left\{A_{t+1} / A_{t}=A_{H}\right\}$, and note that $A_{L} \leq E A_{L} \leq E A_{H}<A_{H}$. Then, we 
adopt the following assumption:

$$
\frac{A_{H}}{A_{H}+E A_{H}}<\alpha<\frac{A_{L}}{A_{L}+\phi \cdot E A_{L}}
$$

This assumption converges to that in Equation (17) as productivity shocks become small. The first inequality ensures that the frictionless economy is dynamically efficient and, as a result, investment is always productive. The second inequality ensures that financial frictions are strong enough to make bubbly equilibria possible.

Consider first the bubbleless equilibrium with productivity shocks. The economy goes through periods of high and low productivity. Periods of high productivity are characterized a large supply of funds and by a high expected productivity, which raises the demand for funds. The former lowers the interest rate while the later increases it (see Figure 4). The relative strength of these effects depends on the persistence of productivity as measured by $\eta$, and the importance of diminishing returns to investment as measured by $\alpha$. If $\eta>0.5 \cdot \alpha$, the effect of productivity on the supply of funds dominates. In this case, when productivity is high the interest rate is low and the gap between the actual and the optimal levels of investment is high. If instead $\eta<0.5 \cdot \alpha$, the effect of productivity on the demand for funds dominates and the opposite is true.

To illustrate how productivity affects the optimal bubble, we extend the economy with 'bubbly episodes' to introduce productivity shocks. To simplify, we assume that transition probabilities for productivity and bubble shocks are independent. With these assumptions, we have that the dynamics of the economy are now given by:

$$
\begin{gathered}
k_{t+1}= \begin{cases}\min \left\{\frac{1-\alpha}{\gamma} \cdot A_{t} \cdot k_{t}^{\alpha},\left[\beta \cdot(\phi \cdot \alpha+\varepsilon \cdot n) \cdot E_{t} A_{t+1}\right]^{\frac{1}{1-\alpha}}\right\} & \text { if } z_{t}=F \\
\min \left\{\frac{1-\alpha}{\gamma} \cdot A_{t} \cdot k_{t}^{\alpha}-\frac{b_{t}}{\gamma},\left[\beta \cdot\left(\phi \cdot \alpha+\left(1-\delta_{j}\right) \cdot n_{j}\right) \cdot E_{t} A_{t+1}\right]^{\frac{1}{1-\alpha}}\right\} & \text { if } z_{t}=B_{j}\end{cases} \\
b_{t}= \begin{cases}0 & \text { if } \quad z_{t}=F \\
\frac{\left(\phi \cdot \alpha+\left(1-\delta_{j}\right) \cdot n_{j}\right) \cdot E_{t-1} A_{t} \cdot k_{t}^{\alpha-1}}{\gamma \cdot\left(1-\delta_{j}\right)} \cdot b_{t-1}+n_{j} \cdot A_{t} \cdot k_{t}^{\alpha} & \text { if } \quad z_{t}=B_{j}\end{cases}
\end{gathered}
$$

Equations (24) and (25) are simple generalizations of Equations (21) and (22) to allow for productivity fluctuations. 
Figure 7 shows simulations for this economy. As before, the simulations start in the steady state and run for 10,000 periods. To produce them, we use the same methodology as in the previous section, except that we now have a process for productivity. In choosing the parameters for this process, we have assumed that $\eta>0.5 \cdot \alpha$. As mentioned, this parameter condition implies that the bubble that fully intermediates wages grows with productivity. This is why in Figure 7 bubbles raise the capital stock when productivity is high but reduce it when productivity is low. This is best exemplified by the long episode that starts after period 6960 and lasts until after period 7000, in which the bubble is large and safe. The capital stock increases during the episode but it fluctuates with productivity. When productivity is high, the capital stock grows because wages are high and the large bubble channels part of these wages to investment. When productivity falls, however, the capital stocks contracts for two reasons: not only are wages lower, but the large bubble diverts part of them away from investment. The evolution of the interest rate confirms this narrative since, by rising above $\beta^{-1}$ whenever productivity is low, it indicates that there is "too much" bubbly collateral and investment is being crowded out. In this example, the equilibrium bubble is too small when productivity is high but it is too large when productivity is small: an 'optimal' bubble would thus be procyclical, amplifying the response of output to productivity shocks. ${ }^{14}$

The general insight of this example is that the relative strength of crowding-in and crowding-out effects changes with the strength of fundamentals. The same amount of bubble creation today, for instance, may have small or large crowding-out effects in the future depending on the evolution of productivity. If future productivity is high and the economy is in the region of partial intermediation, the crowding-out effect of current bubble creation will be small. If instead future productivity is low and the economy is in the region of full intermediation, the crowding-out effect of current bubble creation will be high. In the terminology of

\footnotetext{
${ }^{14}$ More generally, the cyclicality of the bubble that attains full intermediation depends on the shock that is considered. We have also explored, for instance, a specification of the model with financial shocks, i.e. with random fluctuations in $\phi$. These shocks affect the demand for funds but not their supply and, as a result, collateral is pro-cyclical. This means that, to intermediate wages fully, a bubble must be counter-cyclical with respect to $\phi$, so that it reduces the response of output to financial shocks.
} 
the previous section, bubbly episodes may have large "overhang" effects should the economy suffer from a fall in productivity.

Taken together, the examples of the last two sections show that bubbles may expand the economy by providing collateral, but they may also lower investment and output if they grow too large. Can public policy be used to provide the economy with the desired amount of bubbly collateral? We show in this section that the answer to this question is affirmative.

\section{A credit management agency}

We consider next an agency that manages bubbly collateral through credit-market interventions. Subsidizing old entrepreneurs, this agency expands their collateral. Taxing old entrepreneurs, this agency reduces their collateral. The fiscal implications of these interventions are borne by young entrepreneurs. Although these interventions do not directly affect the equilibrium value of the bubble, they enable the agency to "select" an equilibrium allocation.

We refer to this agency as a credit management agency (CMA), since it guarantees the collateral of entrepreneurs at the targeted level. If ex-post the bubble turns out to be too small given the target, the CMA provides additional resources to entrepreneurs. If ex-post the bubble turns out to be too large given the target, the CMA takes away resources from them.

Before turning to the analysis, though, it is important to ponder briefly on what it means to design policy in our environment. The competitive equilibrium is driven by investor sentiment or expectations, as captured by the process $\left\{n_{t}, u_{t}\right\}$. This poses a problem for the evaluation of policy, since the implementation of a given policy may influence expectations themselves and change the underlying process $\left\{n_{t}, u_{t}\right\}$. We avoid this problem by focusing on policies that are expectationally robust, in the sense that they implement the same allocations regardless of agent expectations or investor sentiment. 


\subsection{The model with a credit management agency}

We introduce now a CMA that promises entrepreneurs in period $t$ a transfer of $S_{t}$ units of the economy's consumption good. The transfer $S_{t}$ can be negative and contingent on the state of the economy. If the transfer is positive, its cost is financed by young entrepreneurs. If the transfer is negative, its benefit is distributed to young entrepreneurs. Letting $X_{t}$ denote the agency's tax revenues, we require that the CMA run a balanced budget so that $S_{t}=X_{t}$ in every period $t$.

Define $S_{t+1}^{N}$ as the net resources that this policy provides to the entrepreneurs of generation $t$ in terms of goods in period $t+1$ :

$$
S_{t+1}^{N} \equiv S_{t+1}-\frac{E_{t} R_{t+1}}{\gamma} \cdot X_{t}
$$

That is, $S_{t+1}^{N}$ is the difference between the subsidies that will be obtained in old age and the taxes paid in young age, both expressed in terms of goods in period $t+1$. Insofar as expected subsidies can be pledged by entrepreneurs to cancel credit contracts, this is a wealth transfer that affects collateral. If $S_{t+1}^{N}>0$, the policy creates collateral in period $t$. If $S_{t+1}^{N}<0$, the policy destroys collateral in period $t$. Thus, we refer to $S_{t+1}^{N}$ as collateral creation by the CMA. Using this notation and the budget constraint of the CMA, we can express the dynamics of the policy as follows:

$$
S_{t+1}=\frac{E_{t} R_{t+1}}{\gamma} \cdot S_{t}+S_{t+1}^{N}
$$

The formal similarity between Equations (27) and (5), respectively describing the dynamics of policy and the bubble, hints at some of the results that follow.

The introduction of a CMA does not affect the problem of savers, but it does affect the problem of entrepreneurs. Since entrepreneurs can use subsidies to cancel credit contracts, the collateral constraint in Equation (6) now becomes

$$
R_{t+1} \cdot L_{t} \leq \phi \cdot\left[F\left(K_{t+1}, N_{t+1}\right)-W_{t+1} \cdot N_{t+1}\right]+B_{t+1}+S_{t+1},
$$


while their consumptions are now given by

$$
\begin{aligned}
C_{t, t}^{i} & =L_{t}-K_{t+1}-B_{t}-X_{t}, \\
C_{t, t+1}^{i} & =F\left(K_{t+1}, N_{t+1}\right)-W_{t+1} \cdot N_{t+1}+B_{t+1}+S_{t+1}-R_{t+1} \cdot L_{t} .
\end{aligned}
$$

The only differences between Equations (29)-(30) and Equations (7)-(8) are due to the transfers that are made by the CMA. Borrowers maximize utility in Equation (1) subject to the budget constraints in Equations (29), (30), the credit constraint in Equation (28) and the laws of motion of bubbles and policy in Equations (5) and (27).

The introduction of a CMA does not affect the equilibrium in the markets for labor or bubbles, which are still respectively described by Equations (9) and (10). It does affect the equilibrium in the credit market, though. While the supply of credit is still described by Equation (11), the demand of funds for investment by young entrepreneurs can be written as follows:

$$
E_{t} R_{t+1}=\left\{\begin{array}{lll}
\alpha \cdot A_{t+1} \cdot k_{t+1}^{\alpha-1} & \text { if } \quad E_{t}\left(b_{t+1}^{N}+s_{t+1}^{N}\right) \geq(1-\phi) \cdot \alpha \cdot E_{t} A_{t+1} \cdot k_{t+1}^{\alpha} \\
\frac{\phi \cdot \alpha \cdot E_{t} A_{t+1} \cdot k_{t+1}^{\alpha}+E_{t} b_{t+1}+E_{t} s_{t+1}}{k_{t+1}+\gamma^{-1} \cdot\left(b_{t}+s_{t}\right)} & \text { if } & E_{t}\left(b_{t+1}^{N}+s_{t+1}^{N}\right)<(1-\phi) \cdot \alpha \cdot E_{t} A_{t+1} \cdot k_{t+1}^{\alpha}
\end{array}\right.
$$

As before, Equation (31) says that the interest rate is either the expected marginal product of capital or the ratio of entrepreneur's expected collateral to total credit. The only novelty is that the constraint is affected by the CMA's policies: expected subsidies $E_{t} s_{t+1}$ provide collateral to entrepreneurs and they raise the demand for credit and thus investment, but current taxes $s_{t}$ divert the resources of entrepreneurs and they reduce the share of credit that can be used for investment.

To complete the solution, we need to determine how entrepreneurs use the credit they receive, and this is as follows:

$$
\gamma \cdot k_{t+1}+b_{t}+s_{t}\left\{\begin{array}{lll}
=l_{t} & \text { if } & \beta \cdot \alpha \cdot E_{t} A_{t+1} \cdot k_{t+1}^{\alpha-1}>1 \\
\in\left[0, l_{t}\right] & \text { if } & \beta \cdot \alpha \cdot E_{t} A_{t+1} \cdot k_{t+1}^{\alpha-1}=1
\end{array} .\right.
$$

Equation (32) says that entrepreneurs consume in the first period only if the marginal product of capital 
equals $\beta^{-1}$. Otherwise, entrepreneurs use all the credit they receive to invest, purchase bubbles, and pay taxes.

\subsection{Equilibrium dynamics}

We can now collapse the model with a CMA into the following four equations:

$$
\begin{gathered}
k_{t+1}\left\{\begin{array}{c}
=\frac{(1-\alpha) \cdot A_{t} \cdot k_{t}^{\alpha}-b_{t}-s_{t}}{\gamma} \quad \text { if } \quad \beta \cdot E_{t} R_{t+1}>1 \\
\in\left[0, \frac{(1-\alpha) \cdot A_{t} \cdot k_{t}^{\alpha}-b_{t}-s_{t}}{\gamma}\right] \quad \text { if } \quad \beta \cdot E_{t} R_{t+1}=1
\end{array}\right. \\
E_{t} R_{t+1}=\min \left\{\alpha \cdot E_{t} A_{t+1}, E_{t}\left\{\left(\phi \cdot \alpha+n_{t+1}+m_{t+1}\right) \cdot A_{t+1}\right\}\right\} \cdot k_{t+1}^{\alpha-1}, \\
b_{t+1}=\frac{E_{t} R_{t+1}+u_{t+1}}{\gamma} \cdot b_{t}+n_{t+1} \cdot A_{t+1} \cdot k_{t+1}^{\alpha}, \\
s_{t+1}=\frac{E_{t} R_{t+1}}{\gamma} \cdot s_{t}+m_{t+1} \cdot A_{t+1} \cdot k_{t+1}^{\alpha} .
\end{gathered}
$$

where $m_{t+1}$ measures collateral creation by the CMA as a share of output, i.e. $m_{t+1} \equiv s_{t+1}^{N} /\left(A_{t+1} \cdot k_{t+1}^{\alpha}\right)$. We shall think of $m_{t}$ as the key policy instrument in the model, which is determined by the CMA. Equations (33)-(36) provide a full description of the dynamics of the state variables, i.e. $k_{t}, b_{t}$ and $s_{t}$; for any admissible sequence of productivity and bubble shocks, i.e. $A_{t}, u_{t}$ and $n_{t}$ and for any sequence of policy interventions $m_{t}$. Thus, we refer to these four equations as the law of motion of the system with policy.

Equations (33)-(36) show how policy shocks affect the supply and demand of funds for investment and thus the law of motion. Like bubble shocks, past and present policy choices as captured by $m_{0}, m_{1}, \ldots, m_{t}$ are embedded in subsidies $s_{t}$. Through taxation, these policy choices reduce the present supply of funds available for investment as depicted in Equation (33). Simply put, young entrepreneurs must devote part of their credit to paying for the subsidies promised to the previous generation. Future policy choices as captured by $m_{t+1}$ instead raise the collateral of entrepreneurs, as shown by Equation (34), enabling them to expand their demand for funds and their investment.

Once a CMA is introduced into the model, an equilibrium cannot be defined without specifying policy. Throughout, we take policy as given and describe it by a stochastic process $\left\{m_{t}\right\}$. We adopt the convention 
that $s_{-1}=0$ so that $s_{0}$ is determined by $m_{0}$. We then propose a joint stochastic process for bubble return and bubble creation shocks: $\left\{u_{t}, n_{t}\right\}$, with $E_{t} u_{t+1}=0, b_{t} \geq 0$ and $n_{t} \geq 0$ for all $t$. With this process at hand, we search for a sequence for the state variables $\left(k_{t}, b_{t}, s_{t}\right)$ that satisfies $k_{t} \geq 0$ as well as Equations (33)-(36). If such a sequence exists, we say that the proposed stochastic process is an equilibrium. If such a sequence does not exist, we say that the proposed stochastic process is not an equilibrium.

\subsection{Managing collateral during business cycles}

What can a CMA achieve by taxing and subsidizing credit? A first important result, which follows directly from comparing Equations (33)-(36) with Equations (14)-(16), is that a CMA can use policy to replicate any of the equilibria of the original economy. Take any process $\left\{u_{t}, n_{t}\right\}$ for the bubble return and creation shocks and a corresponding bubble $b_{t}$. Then, the CMA can replicate the equilibrium allocation that would arise under an alternative process $\left\{\hat{u}_{t}, \hat{n}_{t}\right\}$, and the corresponding bubble $\hat{b}_{t}$, by choosing a policy $\left\{m_{t}\right\}$ that satisfies

$$
m_{t} \cdot A_{t} \cdot k_{t}^{\alpha}=\frac{\hat{u}_{t} \cdot \hat{b}_{t-1}-u_{t} \cdot b_{t-1}}{\gamma}+\left(\hat{n}_{t}-n_{t}\right) \cdot A_{t} \cdot k_{t}^{\alpha}
$$

for all $t>0$. This policy guarantees that $s_{t}+b_{t}=\hat{b}_{t}$ and that $E_{t}\left\{\left(m_{t+1}+n_{t+1}\right) \cdot A_{t+1}\right\}=E_{t}\left\{\hat{n}_{t+1} \cdot A_{t+1}\right\}$ in all periods. Thus, the total crowding-out and crowding-in effects of the policy $s_{t}$ together with bubble $b_{t}$ are identical to those of bubble $\hat{b}_{t}$ in the absence of policy. Note that this policy is expectationally robust in the sense that it works for any process $\left\{u_{t}, n_{t}\right\}$.

This result is important because we have seen that markets may provide too little bubbly collateral, which is insufficient to intermediate all wages, or too much of it, which crowds out investment and reduces output and consumption. It therefore seems natural to consider policies that manage the economy's collateral. In particular, we consider policies $\left\{m_{t}\right\}$ that simultaneously satisfy

$$
E_{t}\left\{m_{t+1} \cdot A_{t+1}\right\}=\beta^{-1} \cdot k_{t+1}^{1-\alpha}-E_{t}\left\{\left(\phi \cdot \alpha+n_{t+1}\right) \cdot A_{t+1}\right\}
$$




$$
k_{t+1}=\frac{(1-\alpha) \cdot A_{t} \cdot k_{t}^{\alpha}-b_{t}-s_{t}}{\gamma}
$$

in all periods $t$, and study their effects on steady-state consumption and welfare. Equation (38) guarantees that the proposed policy stabilizes $E_{t} R_{t+1}$ and sets it equal to $\beta^{-1}$ at all times. Equation (39) says that this stabilization must be achieved while guaranteeing that wages are fully intermediated in equilibrium. Through this policy, the CMA effectively "leans against the wind", taxing credit when collateral is excessive and $E_{t} R_{t+1}>\beta^{-1}$ and subsidizing it when collateral is scarce and there is partial intermediation. Note that the policy depends only on observables, since it need only be contingent on aggregate productivity $A_{t}$ and on the bubble shocks $\left\{u_{t}, n_{t}\right\}$.

We can illustrate the effects of such a policy by revisiting the example of a 'quiet' bubbly process, in which $A_{t}=A$ and $\left\{u_{t}, n_{t}\right\}=\{0, n\}$ for all $t$. We have already argued that there is an optimal level of bubble creation in this example, which maximizes output and welfare in the steady state. This bubble, which places the economy at the frontier of the partial and full intermediation regions, corresponds exactly to the one prescribed by our policy rule. Thus, if we use $n^{*}$ to denote such an optimal level of bubble creation and follow Equation (37), a policy that sets $m=n^{*}-n$ in all periods attains the maximum levels of output and welfare in steady state.

The dashed lines in Figure 5 depict the steady state values of capital, credit, the interest rate, utility, the bubble and the subsidy $s$ as a function of $n$ under the proposed policy. In this case, all variables are independent of $n$. Once again, the reason is that the CMA intervenes in the credit market to maximize intermediation while minimizing crowding out effects. In the region of partial intermediation it does so by subsidizing credit payments by old entrepreneurs, i.e. by setting $s>0$, whereas in the region of full intermediation it does so by taxing credit payments by old entrepreneurs, i.e. by setting $s<0$ until $E_{t} R_{t+1}=$ $\beta^{-1}$

These insights are easily extended to the economy with "bubbly episodes" that was analyzed in Section 2.1. This is the same economy as before, with the only difference that it transitions between fundamental 
and bubbly states according to a sunspot variable $z_{t} \in\{F, B\}$. Thus, the optimal bubble is also the same as before, and the corresponding allocation can be implemented by the CMA by setting

$$
m_{t} \cdot A_{t} \cdot k_{t}^{\alpha}=\left(n^{*}-n_{t}\right) \cdot A_{t} \cdot k_{t}^{\alpha}-\frac{u_{t} \cdot b_{t-1}}{\gamma}
$$

in all periods. The dashed lines in Figure 6 show the effects of this policy on the main variables of the economy.The CMA's intervention, which is now state contingent, raises the capital stock in all periods and fully stabilizes it. Whenever bubbly collateral is scarce and the economy is in the partial intermediation region, credit is subsidized until it equals total wages. Whenever collateral is abundant and the interest rate exceeds $\beta^{-1}$, credit is taxed until the $E_{t} R_{t+1}=\beta^{-1}$.

This example illustrates that the CMA's intervention only affects the market for bubbles through its effect on the interest rate. The economy still experiences bubbly episodes and the policy rule has no direct effect over them. Instead, the CMA monitors these fluctuations and intervenes in the market for credit accordingly. When bubbles burst, the CMA steps in and helps entrepreneurs cancel their credit contracts. When bubbles become too large, as in the second and third episodes of the example, the CMA steps in and taxes entrepreneurs. By doing so, the CMA reduces the demand for credit, eliminates the crowding out effect and boosts capital accumulation. Of course, not everyone is happy with this policy: generations with a lot of bubble creation lose because part of their wealth is taxed away. Yet, as the table in Figure 6 confirms, average welfare increases as a result of the intervention.

Figures 5 and 6 depict the effect of our policy rule in economies with no fundamental uncertainty. In this case, the rule is optimal in the sense of maximizing average welfare and output in the steady state. The analysis becomes more complicated in economies with fundamental uncertainty, though. As we have discussed, a level of bubble creation that boosts growth when productivity is high might lead to large crowding-out effects when productivity falls. This complicates the characterization of an optimal bubble. Nonetheless, we apply next our same policy rule to this economy and show that it also raises the average levels of output and welfare in the steady state. 
Figure 7 builds on the example of Section 2.3 and depicts the impact of the policy rule in an economy with both, productivity and bubble shocks. As before, the solid lines represent the values of the different variables in the absence of policy while the dashed lines represent their values under the policy rule. The figure shows that, once more, the policy rule stabilizes the interest rate and it also raises the average capital stock and welfare. The new insight is that the policy has an ambiguous effect on economic volatility. Fluctuations that are driven by bubble shocks are stabilized by the policy, while fluctuations that are driven by productivity shocks are amplified by it.

The reason for this last result is that, under our assumptions, the policy rule is procyclical relative to productivity shocks. When productivity is high, investment is constrained by the demand of funds. Wages are high in these periods and collateral is insufficient to intermediate them all. By following the policy, the CMA increases expected subsidies, raises credit and exacerbates the boom. When productivity is low, however, investment is constrained by the supply of funds. In these times, there is not much that the policy can do to expand output besides taxing borrowing to reduce crowding-out effects. Hence, the policy rule increases the strength of productivity-driven booms relative to productivity-driven recessions. Its overall effect on economic volatility, however, depends on the relative variance of bubble vis-à-vis productivity shocks. In our particular example, as the table in Figure 7 shows, it increases the volatility of both the capital stock and of welfare.

\subsection{Discussion}

The examples of this section show that the bubbly economy provides a new rationale for macroprudential policy. When bubbly collateral is lower than desired, the CMA supplements it by providing funds to entrepreneurs. When bubbly collateral is instead higher than desired, the CMA reduces it by substracting funds from entrepreneurs. This leaning-against-the-wind policy can replicate the "optimal" bubble and maximize steady-state output and consumption. 
Naturally, this policy generates resources when bubbly collateral is high and it requires resources when bubbly collateral is low. Under our assumptions, these losses and gains are borne fully by young entrepreneurs. The policy can therefore be interpreted as an entrepreneurial insurance or "counter-cyclical" fund, to which entrepreneurs contribute during youth in the expectation of receiving a transfer during old age if their collateral turns out to be low. Note however that this insurance is not actuarially fair. If $E_{t} S_{t+1}^{N}>0$, it provides net resources to the entrepreneurs of generation $t$. If $E_{t} S_{t+1}^{N}<0$, it substracts net resources to the entrepreneurs of generation $t$.

Could this policy also be interpreted as conventional monetary policy? After all, it fully stabilizes the interest rate and sets it equal to $\beta^{-1}$. But this is only one part of the policy, though. There are many policies that stabilize the interest rate at that level (i.e., they satisfy Equation (38)) without fully intermediating wages (i.e., they do not satisfy Equation (39)). The crucial part of the policy is that it manages collateral, providing funds to entrepreneurs when collateral is low and taking funds from them when collateral is high.

But perhaps our leaning-against-the-wind policy could be interpreted as unconventional monetary policy. In particular, it could be recast as an asset purchase scheme, not unlike the ones adopted by various governments since the onset of the recent financial crisis. Under this interpretation, the CMA purchases credit contracts from savers at a price of $\phi \cdot \alpha \cdot A_{t} \cdot k_{t}^{\alpha}+b_{t}+s_{t}$. It then collects $\phi \cdot \alpha \cdot A_{t} \cdot k_{t}^{\alpha}+b_{t}$ in payments from old entrepreneurs. When $s_{t}>0$, this interpretation is very natural: it means that the CMA pays "too much" for assets and suffers a loss equal to $s_{t}$. By doing so, though, it relaxes entrepreneurial constraints and raises borrowing ex ante. When $s_{t}<0$, instead, this interpretation of the policy is a bit less natural: it means that the CMA pays "too little" for assets and makes a profit of $s_{t}$. But why would a saver sell her contracts at such a low price? Indeed, this interpretation only makes sense if the CMA has the legal ability to force such sales.

There is another interesting aspect of interpreting our policy as an asset purchase scheme. Up to now, we have assumed that all losses generated by the policy (i.e., $s_{t}>0$ ) are financed through taxation. In reality, 
though, these schemes are mostly financed by issuing government securities. As we now argue, though, nothing changes if we allow the CMA to finance its losses by issuing debt.

\section{The fiscal backstop}

We have assumed so far that the CMA can guarantee any amount of collateral provided that it does not exceed savings, i.e. the upper bound on $X_{t}$ is given by the economy's entire savings. This is obviously an unrealistic assumption. What happens if the CMA's ability to tax young entrepreneurs is limited? We show next that the same conditions that make a policy desirable also guarantee that a credit management agency has enough resources to implement it.

\subsection{The model with debt}

We address this question by assuming that the CMA has a taxation "capacity" $\tau>0$, i.e. a maximum amount that it can tax per effective worker. Clearly, this capacity constraint does not bind for policies that satisfy $s_{t}<\tau$ in all periods. To sustain policies that require transfers $s_{t}>\tau$ in some periods, though, the CMA needs to issue credit contracts. To distinguish these contracts from those issued by entrepreneurs we refer to them as public credit contracts or public debt. We then refer to credit contracts issued by entrepreneurs as private credit contracts or private debt. Public credit contracts issued in period $t$ pay a gross, possibly contingent, amount $D_{t+1}$ units of output in period $t+1$. We use $q_{t}$ to denote the period-t price of a public contract that promises to deliver, in expectation, one unit of output in period $t+1$. With this notation, we can write the budget constraint of the CMA as follows:

$$
S_{t}+D_{t}=X_{t}+q_{t} \cdot E_{t} D_{t+1}
$$

where $q_{t} \cdot E_{t} D_{t+1}$ is the value of public credit contracts issued in period $t$. Equation (40) says that total spending by the CMA in transfers and debt payments cannot exceed total revenues from taxation and the 
sales of public credit contracts.

The main change relative to our previous analysis is that now we have an additional market for public credit contracts. In this market, the CMA supplies debt inelastically. Lender maximization implies that, in equilibrium, the return to public credit contracts must equal the return to private lending, so that $q_{t}=$ $\left(E_{t} R_{t+1}\right)^{-1} .15$ This does not imply, however, that the ex-post interest rate on public and private credit contracts coincide.

Define $D_{t+1}^{N}$ measures the net resources that the evolution of public credit provides to the entrepreneurs of generation $t$ in terms of goods in period $t+1$ :

$$
D_{t+1}^{N} \equiv D_{t+1}-\frac{E_{t} R_{t+1}}{\gamma} \cdot D_{t}
$$

That is, $D_{t+1}^{N}$ is the difference between the public debt that generation $t$ leaves in old age and the public debt that this generation receives in young age, both expressed in terms of goods in period $t+1$. It represents a wealth transfer to generation $t$ and affects its collateral. If $D_{t+1}^{N}>0$, the policy creates collateral in period $t$. If $D_{t+1}^{N}<0$, the policy destroys collateral in period $t$. Thus, we refer to $D_{t+1}^{N}$ as additional collateral creation by the CMA. While $S_{t+1}^{N}$ is the collateral creation that is determined by the evolution of subsidies, $D_{t+1}^{N}$ is the collateral creation that is determined by the evolution of debt and ultimately of taxes.

\subsection{Equilibrium dynamics}

Following steps that are now familiar, we can rewrite the model with a CMA as follows:

$$
\begin{gathered}
k_{t+1}\left\{\begin{array}{l}
=\frac{(1-\alpha) \cdot A_{t} \cdot k_{t}^{\alpha}-b_{t}-s_{t}-d_{t}}{\gamma} \quad \text { if } \quad \beta \cdot E_{t} R_{t+1}>1 \\
\in\left[0, \frac{(1-\alpha) \cdot A_{t} \cdot k_{t}^{\alpha}-b_{t}-s_{t}-d_{t}}{\gamma}\right] \quad \text { if } \quad \beta \cdot E_{t} R_{t+1}=1
\end{array}\right. \\
E_{t} R_{t+1}=\min \left\{\alpha \cdot E_{t} A_{t+1}, E_{t}\left\{\left(\phi \cdot \alpha+n_{t+1}+m_{t+1}^{S}+m_{t+1}^{G}\right) \cdot A_{t+1}\right\}\right\} \cdot k_{t+1}^{\alpha-1}
\end{gathered}
$$

\footnotetext{
${ }^{15}$ To see this note that the consumptions of lenders are now given by $C_{t, t}^{S}=W_{t}-L_{t}-q_{t} \cdot E_{t} D_{t+1}$ and $C_{t, t+1}^{S}=R_{t+1} \cdot L_{t}+D_{t+1}$. Clearly, the demand for public credit contracts will be either zero or infinity if $q_{t} \neq\left(E_{t} R_{t+1}\right)^{-1}$.
} 


$$
\begin{gathered}
b_{t+1}=\frac{E_{t} R_{t+1}+u_{t+1}}{\gamma} \cdot b_{t}+n_{t+1} \cdot A_{t+1} \cdot k_{t+1}^{\alpha} \\
s_{t+1}=\frac{E_{t} R_{t+1}}{\gamma} \cdot x_{t}+m_{t+1}^{S} \cdot A_{t+1} \cdot k_{t+1}^{\alpha} \quad \text { and } \quad x_{t} \leq \tau \\
d_{t+1}=\frac{E_{t} R_{t+1}}{\gamma} \cdot d_{t}+m_{t+1}^{G} \cdot A_{t+1} \cdot k_{t+1}^{\alpha}
\end{gathered}
$$

where $m_{t+1}^{S}$ and $m_{t+1}^{G}$ reflect now collateral creation through both subsidies/taxes and public debt, i.e. $m_{t+1}^{S} \equiv$ $s_{t+1}^{N} /\left(A_{t+1} \cdot k_{t+1}^{\alpha}\right)$ and $m_{t+1}^{G} \equiv d_{t+1}^{N} /\left(A_{t+1} \cdot k_{t+1}^{\alpha}\right)$.

A comparison between Equations (42)-(43) and (33)-(34) shows that the introduction of debt does not substantially affect the supply and demand of funds for investment. As long as $s_{t}^{\prime}=s_{t}+d_{t}$ in all periods, any policy with subsidies $s_{t}^{\prime}$ that is fully financed through taxation can be perfectly replicated with an alternative policy with subsidies $s_{t}<s_{t}^{\prime}$ that is financed partly through taxation and partly through debt. Equations (42) and (43) also show that, like bubbles and subsidies, the introduction of debt financing has conflicting effects on intermediation and capital accumulation. All else equals, debt issued in the past requires taxation and it reduces the supply of funds available for investment. This is why $d_{t}$ enters with a negative sign in Equation (42). Debt issued in the present, though, makes it possible to reduce taxes on the current generation of entrepreneurs thereby enabling them to expand their demand for credit. This is why $m_{t+1}^{G}$ enters with a positive sign in Equation (43).

Now policy consists of a sequence for the triplet $\left\{x_{t}, m_{t}^{S}, m_{t}^{G}\right\}$. We adopt the convention that $s_{-1}=$ $d_{-1}=0$ so that $s_{0}$ and $d_{0}$ is determined by $x_{0}, m_{0}^{S}$ and $m_{0}^{D}$. We then propose a joint stochastic process for bubble return and bubble creation shocks: $\left\{u_{t}, n_{t}\right\}$, with $E_{t} u_{t+1}=0, b_{t} \geq 0$ and $n_{t} \geq 0$ for all $t$. With this process at hand, we search for a sequence for the state variables $\left(k_{t}, b_{t}, s_{t}, d_{t}\right)$ that satisfies $k_{t} \geq 0$ as well as Equations (42)-(46). If such a sequence exists, we say that the proposed stochastic process is an equilibrium. If such a sequence does not exist, we say that the proposed stochastic process is not an equilibrium. 


\subsection{Are there limits to debt financing?}

A quick analysis of Equations (42)-(46) suggests that debt financing can help achieve policies that would not be feasible otherwise due to the fiscal constraint that $x_{t} \leq \tau$. What ensures, though, that the government can issue public debt contracts? That is, what are the limits to debt financing? This question is relevant because an important difference between taxes and debt is that paying taxes is mandatory while purchasing debt is not. In any period $t$, the debt issued by the CMA is backed by taxes but also by the expectation of new debt that will be issued in period $t+1$. If this expectation changes, so might the willingness of savers to hold debt. Thus, debt financing seems subject to changes in investor sentiment that might limit the CMA's ability to manage the economy's collateral. In short, public credit might be just as bubbly as private credit.

To see whether this concern is justified, we focus on the case in which the CMA uses the policy rule derived in Section 3.3 to intermediate all wages while setting $E_{t} R_{t+1}=\beta^{-1}$ for all $t$. We assume that $\tau$ is small, so that debt financing is is required to fund the desired subsidies. In equilibrium, the most that the CMA can promise to repay at time $t+1$ is given by

$$
E_{t} d_{t+1} \leq \tau+\gamma \cdot \beta \cdot E_{t}\left\{E_{t+1} d_{t+2}\right\}
$$

i.e. expected debt payments cannot exceed the expected resources obtained through taxation and through the issue of new debt. But the expected debt payments that the CMA can make at time $t+2$ are themselves limited by expected taxation and the sale of new debt at $t+3$, and so on. Iterating this process forward we obtain an upper bound for debt payments:

$$
E_{t} d_{t+1} \leq \tau \cdot \sum_{j=0}^{\infty}(\gamma \cdot \beta)^{j}+\lim _{T \rightarrow \infty}\left[(\gamma \cdot \beta)^{T} \cdot E_{t} d_{t+T}\right]
$$

Equation (47) provides an expression for the CMA's fiscal backstop. It says that expected debt payments are backed by fundamental resources, which correspond to the net present value of taxes, and by bubbly resources, which correspond to the public debt that is expected to be rolled over forever. The key aspect of this expression is that, since $\gamma \cdot \beta>1$, the fundamental resources of the CMA are infinite for any positive 
value of $\tau$, regardless of how small it is. Thus, even if the CMA must issue debt to finance its policies, it can always do so without being exposed to roll-over crises: the reason is that, no matter how large debt payments are, they are always fully backed by future taxes. In the bubbly economy, the fiscal backstop of the CMA is unlimited!

The intuition behind this result is quite natural. The CMA's fiscal backstop includes all future taxes, including those that will be paid by generations that are yet to be born. These tax revenues grow with the economy. When collateral is scarce and output is below potential, though, this growth rate is higher than the market interest rate and the net present value of tax revenues is unbounded. Thus, the same condition that makes bubbly episodes possible guarantee that, even if the CMA must issue debt to finance its policies, this debt is not prone to a rollover crisis because it is fully backed by tax revenues.

\section{What have we learned?}

So what do we take home from this paper? Credit booms and busts are a fact of life in modern economies. There is a widespread view among macroeconomists that fluctuations in collateral are an important driver of these fluctuations in credit. This paper builds on this view and makes the following observations:

1. Economies with binding borrowing constraints have two types of collateral, fundamental and bubbly. Fluctuations in both types of collateral generate boom-bust cycles in credit, investment and growth. These fluctuations might be driven by traditional or fundamental shocks, but also by changes in investor sentiment or market expectations. Both types of shock affect the amounts of fundamental and bubbly collateral.

2. Bubbly collateral raises equilibrium credit (“crowding-in”) but diverts part of this credit away from investment (“crowding-out"). When bubbles are small, the crowding-in effect dominates and investment and output increase. When bubbles are large, the crowding out effect dominates and investment 
and output are low. There is therefore an "optimal" bubble size that trades off these two effects to maximize long-term output and consumption.

3. Markets are generically unable to provide the optimal amount of bubbly collateral, but a credit management agency can replicate the "optimal" bubble allocation by taxing credit when bubbly collateral is excessive and subsidizing it when it is insufficient. Such a policy can be characterized as leaningagainst-the-wind, but not as a policy of preventing bubbles. It cannot be characterized as a bailout policy either, since the credit-market interventions that are required to implement it pay for themselves. To some extent, we argue that this policy can be interpreted as a scheme in which the credit management agency purchases assets to manage the economy's stock of collateral.

These results provide a coherent and rich view of credit booms and busts, in which both fundamental and bubbly collateral play a key role. They also provide a useful blueprint to guide policy in dealing with credit bubbles. But the theory has limitations and there is much work to be done.

A first limitation of the model is that it depicts situations in which only the total amount of bubbly collateral matters. But there are situations in which it is not just the amount, but also the type of bubbly collateral that is important. An economy with financial intermediaries that collect deposits and lend to entrepreneurs, for instance, will require different types of bubbly collateral to back deposit and loan contracts. An economy in which savers differ according to their risk aversion, in turn, might require different types of collateral to back safe and risky credit contracts. In both cases, there may be too much collateral of one type but too little collateral of the other type. Thus, to improve on market outcomes, the CMA must simultaneously subsidize some types of credit while taxing others. ${ }^{16}$

A second limitation of the model is that it considers a closed economy. But one of the characteristics of recent credit booms and busts is that they have been associated with surges and sudden stops in capital flows together with large fluctuations in real exchange rates. It would be interesting to develop an open-economy

\footnotetext{
${ }^{16}$ We refer the reader to an online appendix for a more formal treatment of these issues.
} 
version of the model that allows us to investigate the role of capital flows and exchange rates in shaping these credit booms and busts. Moreover, this extension would allows us also to study the international transmission of credit bubbles and the international coordination of credit management policies like the ones we have analyzed here. ${ }^{17}$

A third limitation of the model is that everyone observes the gap between the optimal bubble and the existing one. Thus, the role of policy is simply to bridge this gap. Reality is more complicated because market participants and policymakers may be uncertain as to whether fluctuations are driven by fundamental or bubbly collateral. Introducing this type of uncertainty is an important next step in this research agenda.

A fourth limitation of the model is that it essentially takes fundamental collateral as exogenous. One may think, though, that fundamental collateral is "produced" by the financial system when it invests in the screening and monitoring of entrepreneurs. Bubbly collateral provides an inexpensive alternative to fundamental collateral because it is sustained by market expectations. This may entail costs, however: by discouraging investment in fundamental collateral, bubbly collateral may be expansionary in the short run at the expense of larger downturns when bubbly episodes end. Taking into account these negative incentive effects of bubbles, and analyzing how they impact the design of policy, is another exciting next step in this research agenda.

\section{References}

[1] Aoki, K. and K. Nikolov (2011), "Bubbles, Banks and Financial Stability”, working paper CARF-F253, The University of Tokio.

[2] Bernanke, B. and M. Gertler (1989), "Agency Costs, Net Worth and Business Fluctuations", American Economic Review 79, 14-31.

\footnotetext{
${ }^{17}$ For such an extension, see Martin and Ventura (2015).
} 
[3] Caballero, R. and A. Krishnamurthy (2006), "Bubbles and Capital Flow Volatility: Causes and Risk Management”, Journal of Monetary Economics 53(1), 33-53.

[4] Claessens, S., A. Kose and M. Terrones (2011), "Financial Cycles: What? How? When?", NBER International Seminar on Macroeconomics, University of Chicago Press, 7(1), 303 - 344.

[5] Dang, T.V., G. Gorton and B. Holmstrom (2012), "Ignorance, Debt and Financial Crises", mimeo, Yale.

[6] Dell'Ariccia, G., D. Igan, L. Laeven and H. Tong, with B. Bakker and J. Vandenbussche (2012), "Policies for Macrofinancial Stability: How to Deal with Credit Booms", IMF Staff Discussion Note, SDN $12 / 06$.

[7] Dell'Ariccia, G., D. Igan and L. Laeven (2012), “Credit Booms and Lending Standards: Evidence from the Subprime Mortgage Market”, Journal of Money, Credit, and Banking 44(2-3), 367-384..

[8] Dell'Ariccia, G. and R. Marquez (2006), "Lending Booms and Lending Standards", The Journal of Finance 51(5), 2511-2546.

[9] Diba, B. and H. Grossman (1988), “The Theory of Rational Bubbles in Stock Prices", Economic Journal, 98(3), 746-754.

[10] Farhi, E. and J. Tirole (2011), "Bubbly Liquidity”, Review of Economic Studies 79, 678-706.

[11] Farhi, E. and J. Tirole (2012), "Collective Moral Hazard, Maturity Mismatch and Systemic Bailouts," American Economic Review 102, 60-93.

[12] Geerolf, F. (2013), "Reassessing Dynamic Efficiency”, mimeo, Toulouse School of Economics.

[13] Gertler, M., and N. Kiyotaki (2010), "Financial Intermediation and Credit Policy in Business Cycle Analysis”, in Friedman and Woodford, Handbook of Monetary Economics, Vol. 3A, Elsevier. 
[14] Gorton, G. and P. He (2008), "Bank Credit Cycles", Review of Economic Studies 75(4), 1181-1214.

[15] Gorton, G. and G. Ordoñez (2014), “Collateral Crises”, American Economic Review 104(2), 343-378.

[16] Gourinchas, P.O., R. Valdes and O. Landerretche (2001), "Lending Booms: Latin America and the World", Economia 1(2), 47-99.

[17] Kiyotaki, N., and J. Moore (1997), “Credit Cycles”, Journal of Political Economy 105, 211-248.

[18] Kiyotaki, N. and J. Moore (2008), "Liquidity, Business Cycles and Monetary Policy”, mimeo, Princeton University.

[19] Kocherlakota, N. (2009), "Bursting Bubbles: Consequences and Cures”, mimeo, Federal Reserve Bank of Minneapolis.

[20] Martin, A. (2008), "Endogenous Credit Cycles”, mimeo, CREI.

[21] Martin, A. and J. Ventura (2011), "Theoretical Notes on Bubbles and the Current Crisis", IMF Economic Review 59, 6-40.

[22] Martin, A. and J. Ventura (2012), "Economic Growth with Bubbles", American Economic Review 102, 3033-3058.

[23] Martin, A. and J. Ventura (2015), "International Transmission of Credit Bubbles: Theory and Policy", mimeo, CREI.

[24] Matsuyama, K. (2007), “Credit Traps and Credit Cycles”, American Economic Review 97(1), 503-516.

[25] Mendoza, E. and M. Terrones (2012), “An Anatomy of Credit Booms and their Demise”, WP 18379, NBER.

[26] Mian, A. and A. Sufi (2009), “The Consequences of Mortgage Credit Expansion: Evidence from the U.S. Mortgage Default Crisis”, The Quarterly Journal of Economics 124(4), 1449-1496. 
[27] Miao, J. and P. Wang (2011), "Bubbles and Credit Constraints", mimeo, Boston University.

[28] Rancière, R., A. Tornell and F. Westermann (2008), "Systemic Crises and Growth", The Quarterly Journal of Economics 123(1), 359-406.

[29] Ruckes, M. (2004), "Bank Competition and Credit Standards", The Review of Financial Studies 17(4), 1073-1102.

[30] Samuelson, P. (1958), "An Exact Consumption-loan Model of Interest with or without the Social Contrivance of Money", Journal of Political Economy 66, 467-482.

[31] Schularick, M. and A. Taylor (2012), "Credit Booms Gone Bust: Monetary Policy, Leverage Cycles and Financial Crises, 1870-2008”, American Economic Review 102(2), 1029-1061.

[32] Tirole, J. (1985), “Asset Bubbles and Overlapping Generations”, Econometrica 53 (6), 1499-1528.

[33] Ventura, J. (2011), “Bubbles and Capital Flows”, Journal of Economic Theory 147 (2), 738-758. 


\section{Credit/GDP Trends for OECD Countries}

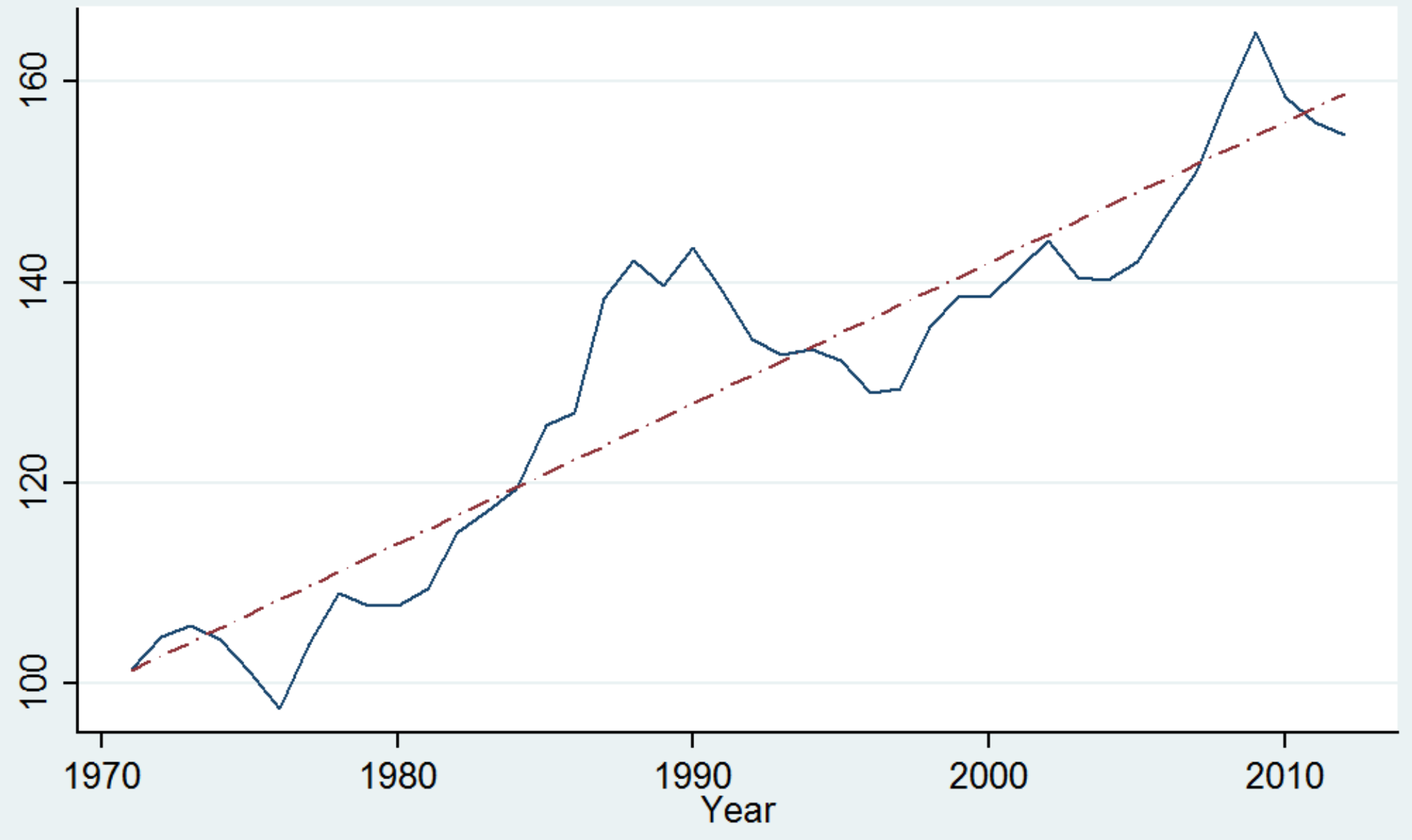

\section{Credit/GDP $\quad-\cdots \cdot \cdot-\cdot$ Fitted values}

Date Source - Long series on credit to private non-financial sectors by the Bank of International Settlements (2013). The plot above includes all OECD countries except Chile, Estonia, Israel, Slovak Republic and Slovenia. Slovak Republic joined the OECD in 2000, the rest in 2010. 


\section{Credit/GDP Trend}
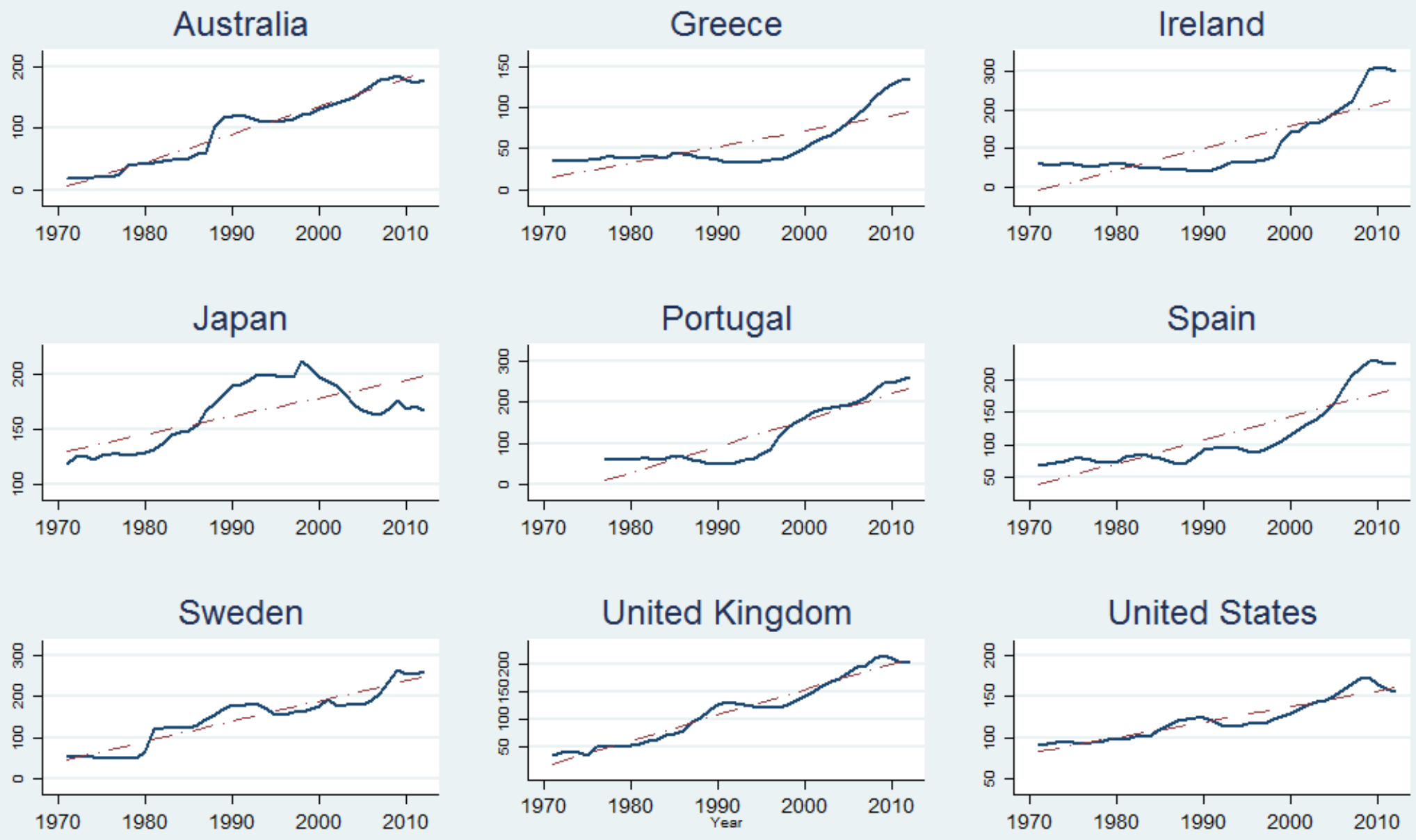

\section{Credit/GDP $\quad \ldots+\cdots$ Fitted values}

Date Source - Long series on credit to private non-financial sectors by the Bank of International Settlements (2013).

Figure 2: Selected OECD Countries with Credit/GDP trends 


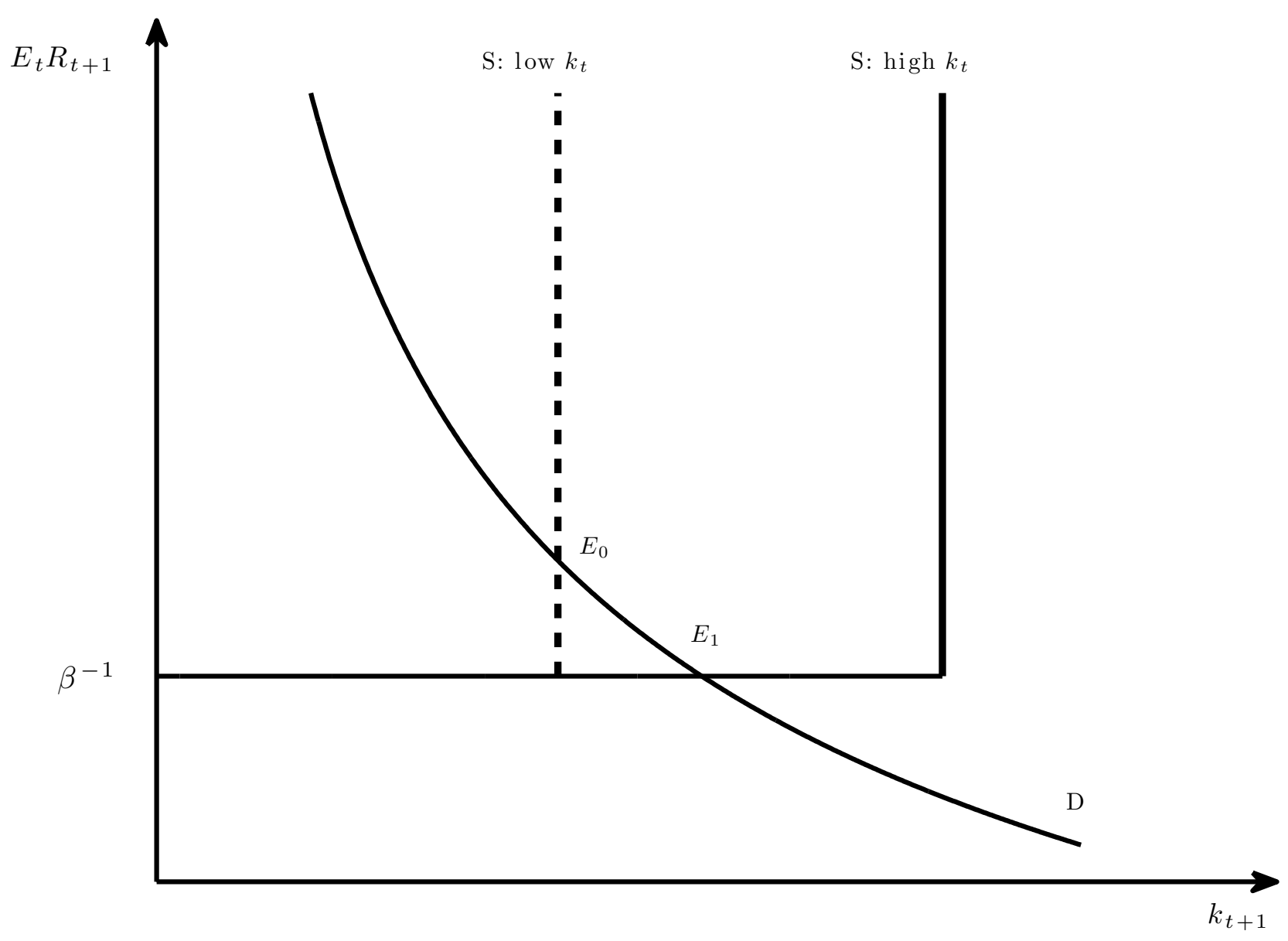

Figure 3: Demand and supply of funds for investments 

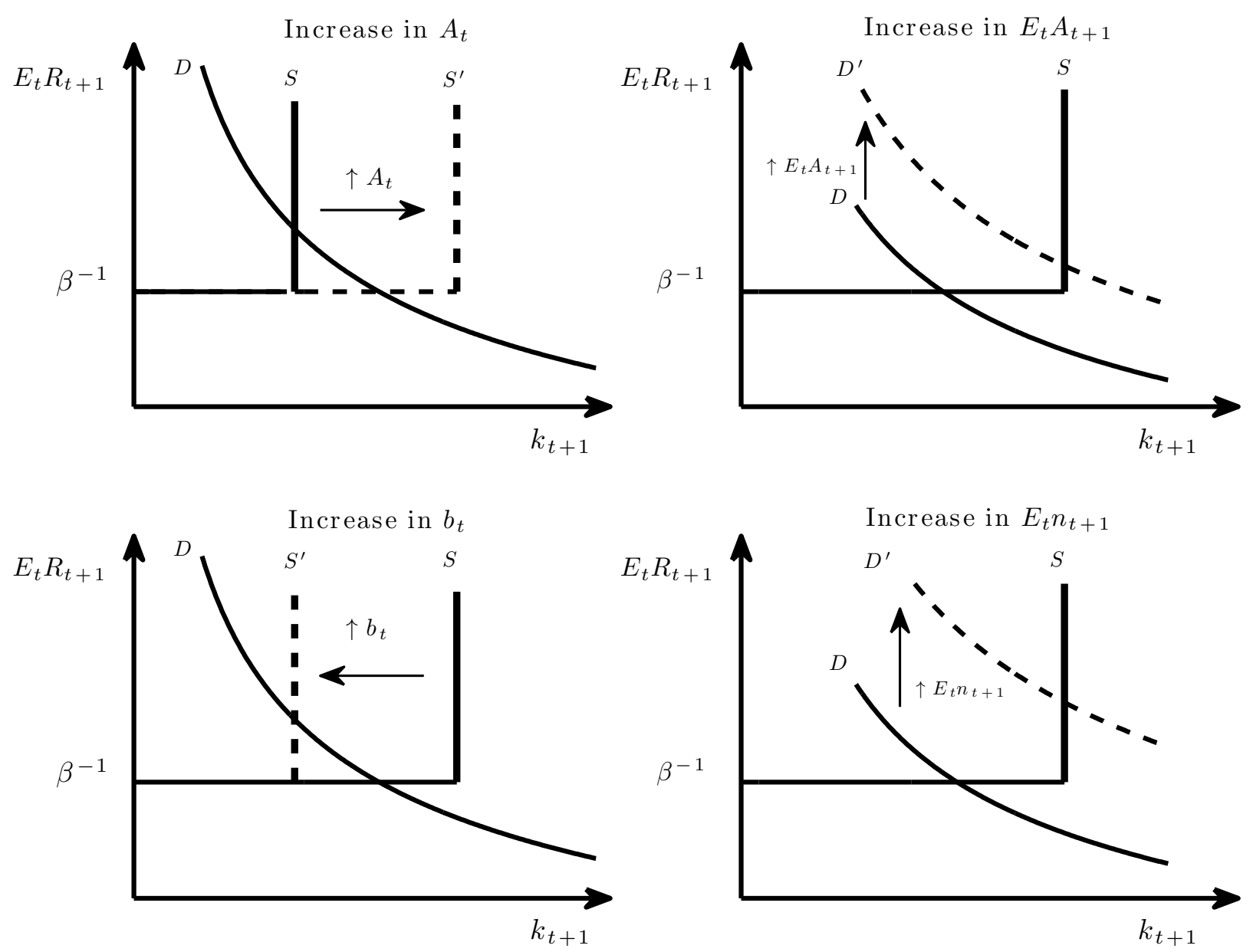

Figure 4: Demand and supply of funds in the presence of shocks 

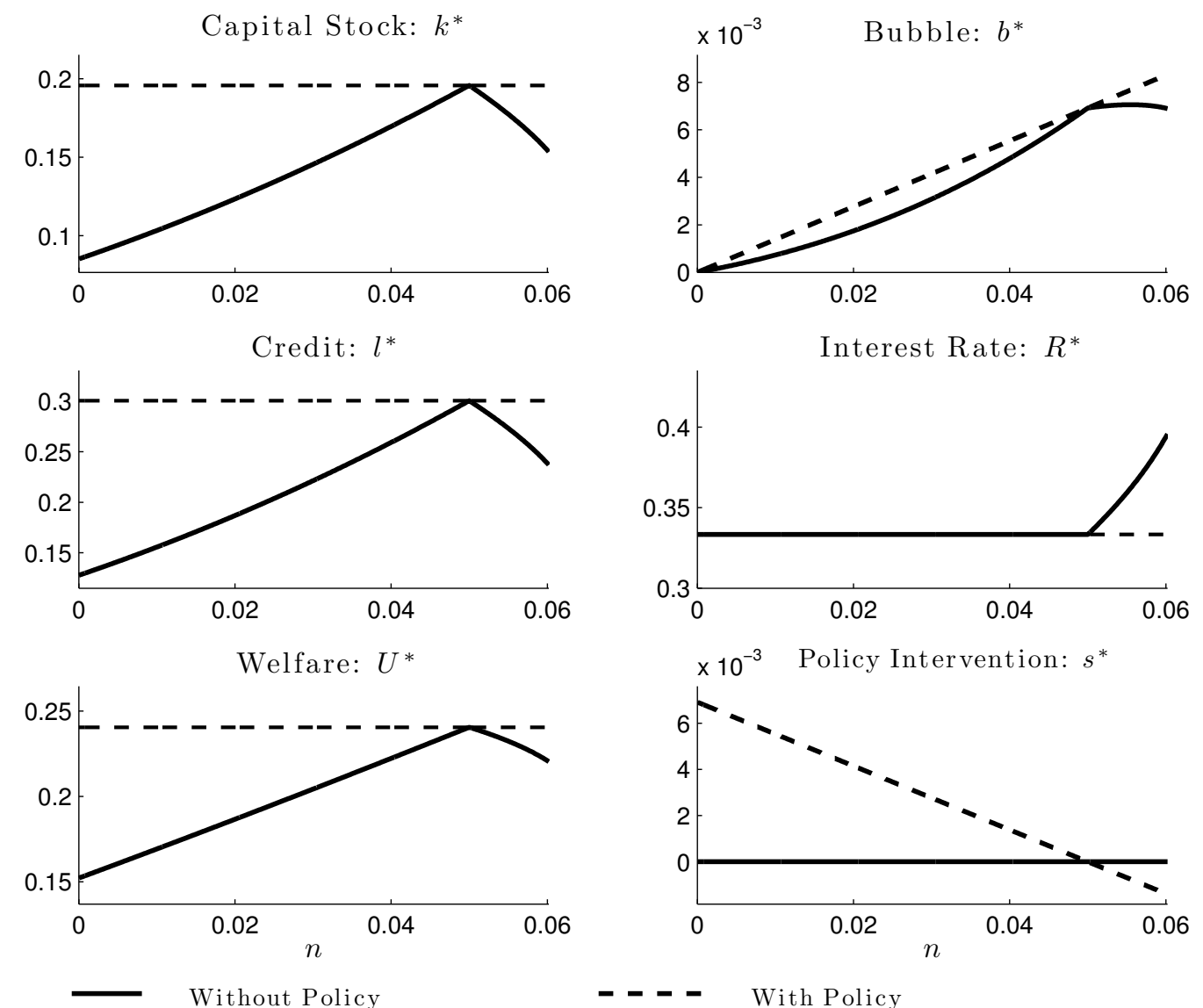

$\times 10^{-3}$ Policy Intervention: $s^{*}$

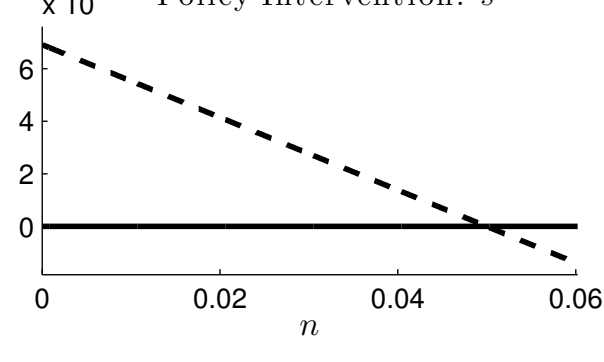

- - - With Policy

Figure 5: An economy with a deterministic bubble and no productivity shocks (with and without policy) 
Capital Stock, $k_{t+1}$
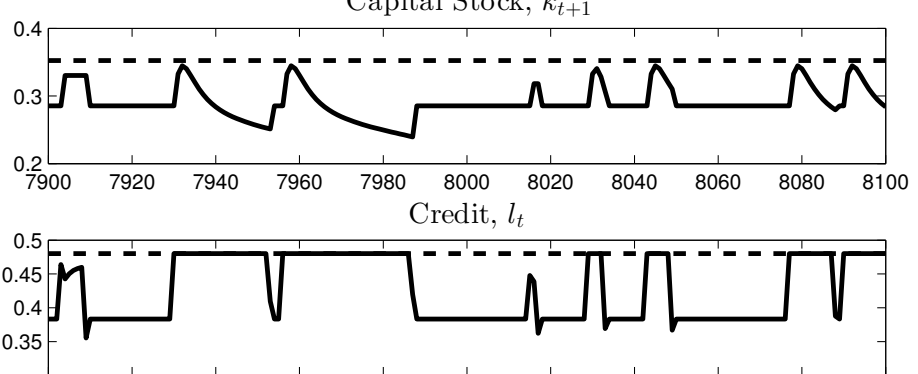

$\begin{array}{lllllllllll}7900 & 7920 & 7940 & 7960 & 7980 & 8000 & 8020 & 8040 & 8060 & 8080 & 8100\end{array}$ Interest Rate, $E_{t} R_{t+1}$
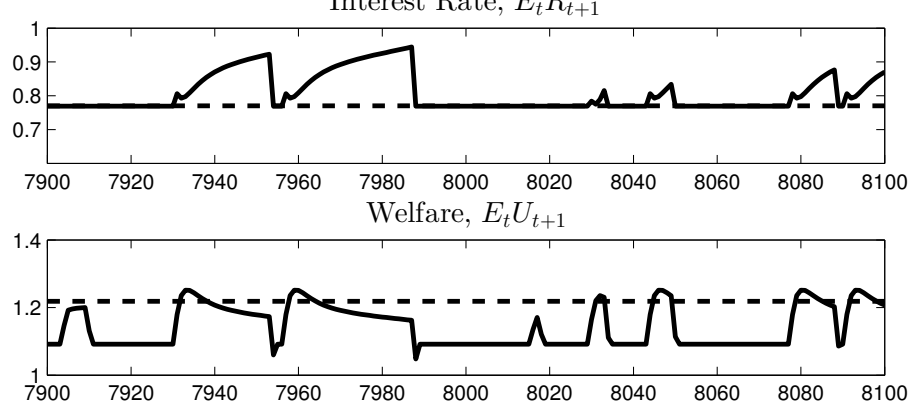

Without Policy

- - - - - - With Policy
Bubble, $b_{t}$
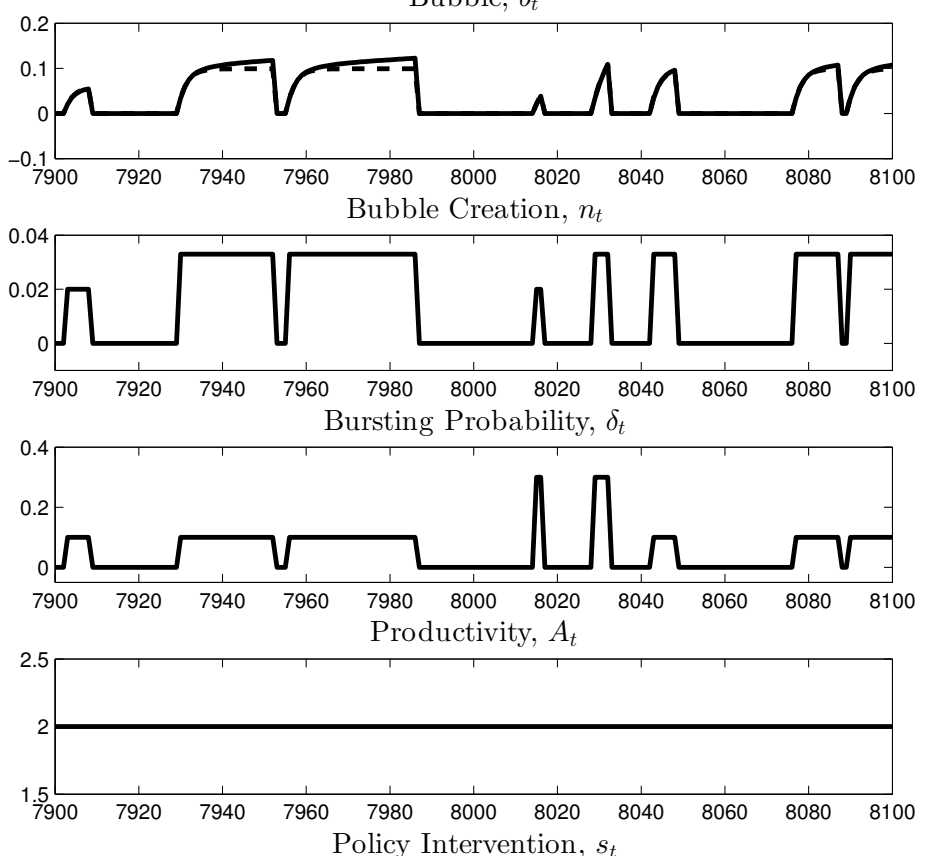
Policy Intervention, $s_{t}$

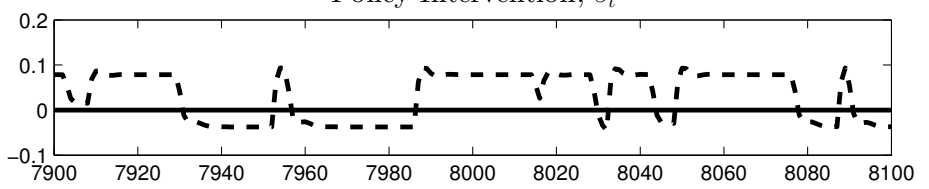

\begin{tabular}{|c|c|c|c|}
\cline { 3 - 4 } \multicolumn{2}{c|}{} & Without Policy & With Policy \\
\hline \multirow{2}{*}{$k_{t+1}$} & $\mu$ & 0.297 & 0.337 \\
\cline { 2 - 4 } & $s . d$. & 0.027 & 0 \\
\hline \multirow{2}{*}{$E_{t} U_{t+1}$} & $\mu$ & 1.136 & 1.202 \\
\cline { 2 - 4 } & $s . d$. & 0.079 & 0 \\
\hline
\end{tabular}

Figure 6: An economy with bubble shocks but without productivity shocks (with and without policy) 
Capital Stock, $k_{t+1}$
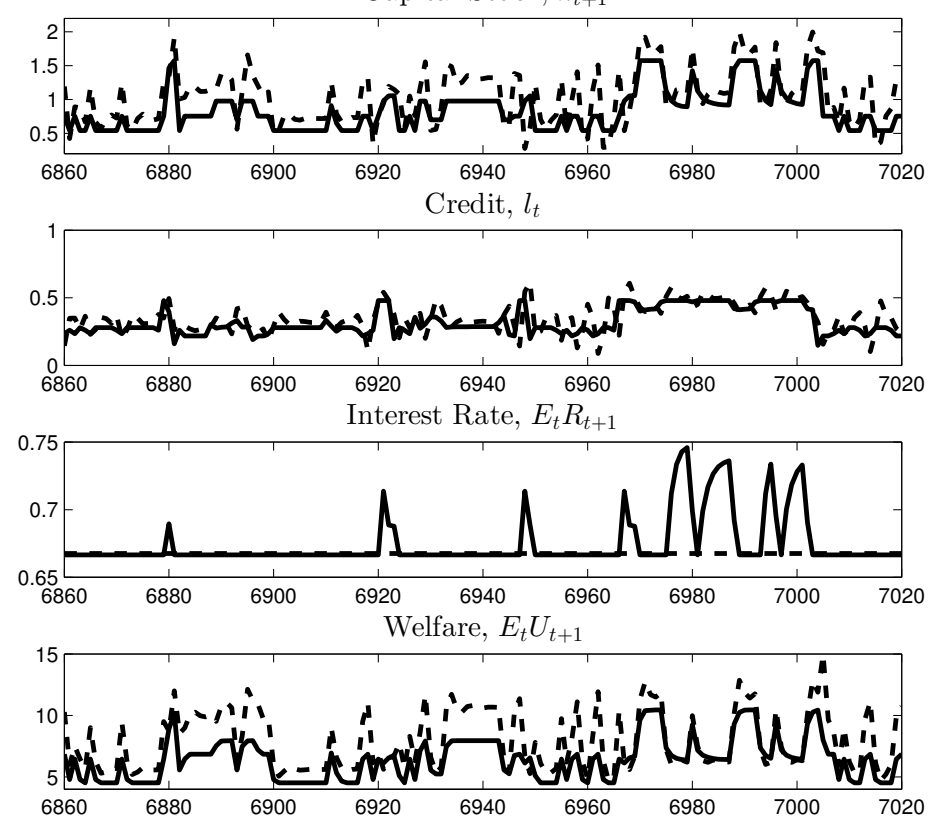

Without Policy

- - - - - - With Policy
Bubble, $b_{t}$
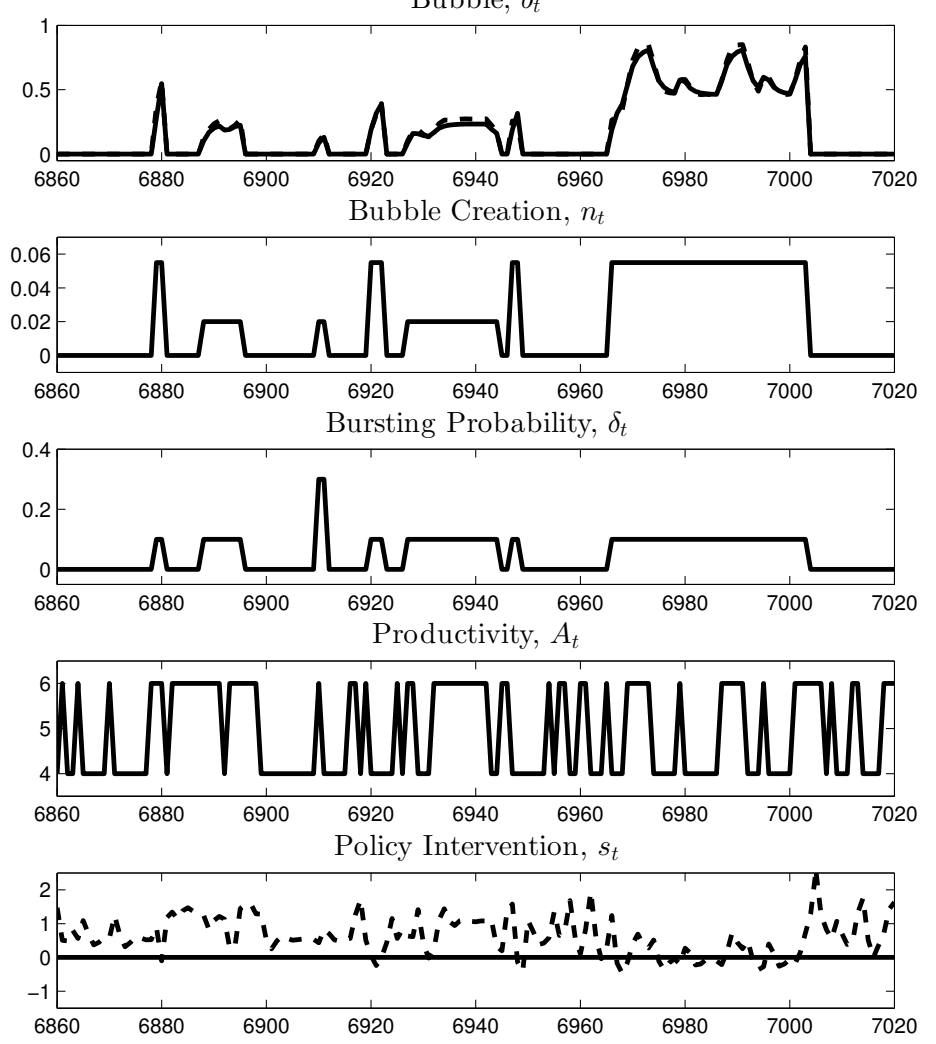

Figure 7: An economy with bubble and productivity shocks (with and without policy) 